\title{
Development of Stable Influenza Vaccine Powder Formulations: Challenges and Possibilities
}

\author{
J-P. Amorij, ${ }^{1}$ A. Huckriede, ${ }^{2}$ J. Wilschut, ${ }^{2}$ H. W. Frijlink, ${ }^{1}$ and W. L. J. Hinrichs ${ }^{1,3}$
}

Received December 30, 2007; accepted February 13, 2008; published online March 13, 2008

\begin{abstract}
Influenza vaccination represents the cornerstone of influenza prevention. However, today all influenza vaccines are formulated as liquids that are unstable at ambient temperatures and have to be stored and distributed under refrigeration. In order to stabilize influenza vaccines, they can be brought into the dry state using suitable excipients, stabilizers and drying processes. The resulting stable influenza vaccine powder is independent of cold-chain facilities. This can be attractive for the integration of the vaccine logistics with general drug distribution in Western as well as developing countries. In addition, a stockpile of stable vaccine formulations of potential vaccines against pandemic viruses can provide an immediate availability and simple distribution of vaccine in a pandemic outbreak. Finally, in the development of new needle-free dosage forms, dry and stable influenza vaccine powder formulations can facilitate new or improved targeting strategies for the vaccine compound. This review represents the current status of dry stable inactivated influenza vaccine development. Attention is given to the different influenza vaccine types (i.e. whole inactivated virus, split, subunit or virosomal vaccine), the rationale and need for stabilized influenza vaccines, drying methods by which influenza vaccines can be stabilized (i.e. lyophilization, spray drying, spray-freeze drying, vacuum drying or supercritical fluid drying), the current status of dry influenza vaccine development and the challenges for ultimate market introduction of a stable and effective dry-powder influenza vaccine.
\end{abstract}

KEY WORDS: analytical challenges; influenza vaccine; lyophilization; needle-free dosage forms; spray drying; spray-freeze drying; stability; stock piling for pandemics; virosomes.

\section{INTRODUCTION}

Yearly recurrent influenza epidemics and the threat of an influenza pandemic remain major public health concerns. Few infectious diseases cause such a huge annual toll of morbidity,

\footnotetext{
${ }^{1}$ Department of Pharmaceutical Technology and Biopharmacy, University of Groningen, Antonius Deusinglaan 1, 9713 AV, Groningen, The Netherlands.

${ }^{2}$ Department of Medical Microbiology, Molecular Virology Section, University Medical Center Groningen, University of Groningen, Antonius Deusinglaan 1, 9713 AV, Groningen, The Netherlands.

${ }^{3}$ To whom correspondence should be addressed. (e-mail: w.l.j. hinrichs@rug.nl)
}

ABBREVIATIONS: APC, antigen presenting cell; CA, coldadapted; CTL, cytotoxic T lymphocyte; DC, dendritic cell; HA, haemagglutinin; HES, hydroxyethylstarch; i.m., intramuscular; LAIV, live attenuated influenza vaccine; M1, matrix protein of influenza; M2, proton channel of influenza A; MDCK, Madin-Darby canine kidney; MHC, major histocompatibility; NA, neuraminidase; NB, protonchannel of influenza B; PBS, phosphate buffered saline; $P_{\mathrm{c}}$, critical pressure; POPC, 1-Palmitoyl-2-oleoyl-sn-glycero-3phosphocholine; RH, relative humidity; SDLM, spray dried lipid based micro particles; $\mathrm{SC}-\mathrm{CO}_{2}$, supercritical $\mathrm{CO}_{2} ; \mathrm{SCF}$, supercritical fluid; SFD, spray-freeze drying; $T_{\mathrm{c}}$, critical temperature; $T_{\mathrm{g}}$, glass transition temperature; $T_{g}^{\prime}$, glass transition temperature of the maximal freeze-concentrated fraction; $T_{\mathrm{m}}$, melting temperature; $T_{\mathrm{e}}$, eutectic temperature; VVM, vaccine vial monitor; $\mathrm{WHO}$, World Health Organization; WIV, whole inactivated virus. mortality, and economic loss as influenza. Each year, influenza affects millions of people (estimates go up to $5-15 \%$ of the world population (1)). The symptoms of human infection range from typical influenza-like effects, such as fever, cough, sore throat and muscle aches, to viral pneumonia, acute respiratory distress, and other severe and potentially lifethreatening complications (2,3). For epidemic influenza strains this is especially true for the elderly and other highrisk populations whereas pandemic strains may affect all age groups.

Although antiviral drugs can be used for prophylaxis and therapy of influenza virus infections, vaccination is recognized as the most cost-effective method for controlling the disease. Vaccination represents the cornerstone for influenza prevention. Many countries recommend influenza vaccination against epidemic influenza for persons who are at increased risk for influenza complications, persons older than 65 years, residents of nursing homes and health-care workers (4). However, in a pandemic situation influenza vaccines are expected to form the main prophylactic measure for all age groups against pandemic influenza (5).

Until today, the induction of an adequate level of virusneutralizing antibodies in the serum is considered as the primary criterion for influenza vaccine efficacy. These antibodies are mainly directed against the major viral envelope glycoprotein, haemagglutinin (HA). Current influenza vaccines are mostly inactivated formulations composed of whole inactivated virus, split virus or subunit antigen, i.e. purified 
HA and neuraminidase (NA). However, recently also virosomes and a cold-adapted live influenza vaccine have entered the market.

Today's influenza vaccines are all formulated as liquids. In the aqueous environment they are subjected to physical and chemical degradation that may lead to inactivation. Examples of such degradation processes are aggregation, denaturation, loss of the spring-loaded conformation of HA, hydrolysis and oxidation.

Elevated temperatures increase the rate of inactivation of the vaccine compounds, while temperatures below the freezing point of the dispersion cause formation of ice and concentration of solute, processes that both may damage the antigen. Therefore (inactivated) influenza vaccines have to be stored within the narrow temperature range of 2 to $8^{\circ} \mathrm{C}$. This relatively narrow temperature range requires a wellcontrolled cold chain, which makes the process of distribution and storage complicated and expensive. An influenza vaccine that is stable at ambient temperatures and not sensitive to freezing stresses would reduce the dependency on cold-chain facilities and would therefore be attractive for the integration of the vaccine logistics with general drug distribution, especially in developing countries. Moreover this would reduce the risk of vaccine losses caused by "off-label" storage. Overall this would result in enormous annual savings. In addition, a stable vaccine formulation would facilitate stockpiling of potential vaccines against pandemic viruses and thus provide an immediate availability and simple distribution of vaccine in a pandemic situation in both Western and developing countries.

Current inactivated influenza vaccines are generally administered via intramuscular (i.m.) injection, while needlefree delivery may provide several potential advantages such as elimination of pain and fear caused by the injection, easier and faster vaccine distribution and administration, reduced costs and improved immune responses including mucosal immune responses in the respiratory tract (6-8). So far, approaches for alternative vaccine delivery suffer from several limitations or by practical problems that frequently result in inadequate antibody responses or even in a state of immunological tolerance (9). As a result, marketed influenza vaccines, being in the liquid state, are still mainly administered through injection. The development of new administration and targeting strategies may be facilitated by dried vaccine formulations.

An influenza vaccine powder may have the potential to reduce the dependency on cold-chain facilities and enable stockpiling and vaccine targeting strategies. In general, conversion of biologically active macromolecules, such as proteins, vaccines and gene delivery systems into a drypowder formulation using suitable excipients and processes results in more stable products which can be stored at room temperature for longer time. In the development of new needle-free dosage forms, such dry formulations offer the opportunity of a more stable product, combined with the facilitation of new or improved targeting strategies.

This paper intends to provide an up-to-date perspective on the development of dried influenza vaccines, covering its challenges and possibilities, including recent developments and achievements in this field. After a brief introduction on the structure of the influenza virus, five interrelated topics are discussed sequentially: (1) types of influenza vaccines, (2) rationales for the development of dry vaccine formulations, (3) drying methods for different influenza vaccines, (4) analytical challenges and (5) the application of dry influenza vaccine formulations for the future.

\section{INFLUENZA VIRUS}

\section{Structure}

Influenza virus (Fig. 1) is a respiratory pathogen belonging to the family of the Orthomyxoviridae (10). There are three types of influenza $(\mathrm{A}, \mathrm{B}, \mathrm{C})$ distinguished by the antigenic differences in the major internal proteins of the virus, i.e. nucleoprotein (NP) and matrix protein (M1). These three types of viruses differ in their pathogenicity and genome organization. Influenza $\mathrm{A}$ and $\mathrm{B}$ viruses are the types that most commonly cause human disease. Among influenza A viruses are subdivided further into subtypes based on the surface antigens, HA and NA. In influenza A viruses 16 subtypes of HA (H1-H16) and 9 subtypes of NA (N1-N9) have been found to date.

The genome of influenza A and B consists of negativestranded segmented RNA (eight segments). Each RNA segment is complexed with multiple copies of NP and form, together with the polymerase complex consisting of PA, PB1 and $\mathrm{PB} 2$, the ribonucleoprotein (RNP) complex. In the virion particle, eight RNP complexes are surrounded by a shell of matrix protein (M1), which is enveloped by a lipid bilayer. Besides the two surface glycoproteins, HA and neuraminindase (NA), the envelope contains a proton channel (M2 in influenza $\mathrm{A}$ and $\mathrm{NB}$ in influenza B). HA and NA are the major antigenic determinants of influenza $A$ viruses and as such serve as the basis for subtype classification.

HA, the major surface glycoprotein of the influenza virus, is responsible for both attachment of the virus to sialicacid-containing receptors on the host cell surface and fusion of the viral and endosomal membrane. HA is a trimer $(\sim 225 \mathrm{kD})$ of three identical monomers ( $75 \mathrm{kD}$; Fig. 2). Each HA monomer consists of the polypeptides HA1 $(\sim 50 \mathrm{kD})$ and HA2 $(\sim 25 \mathrm{kD})$, which are linked by two

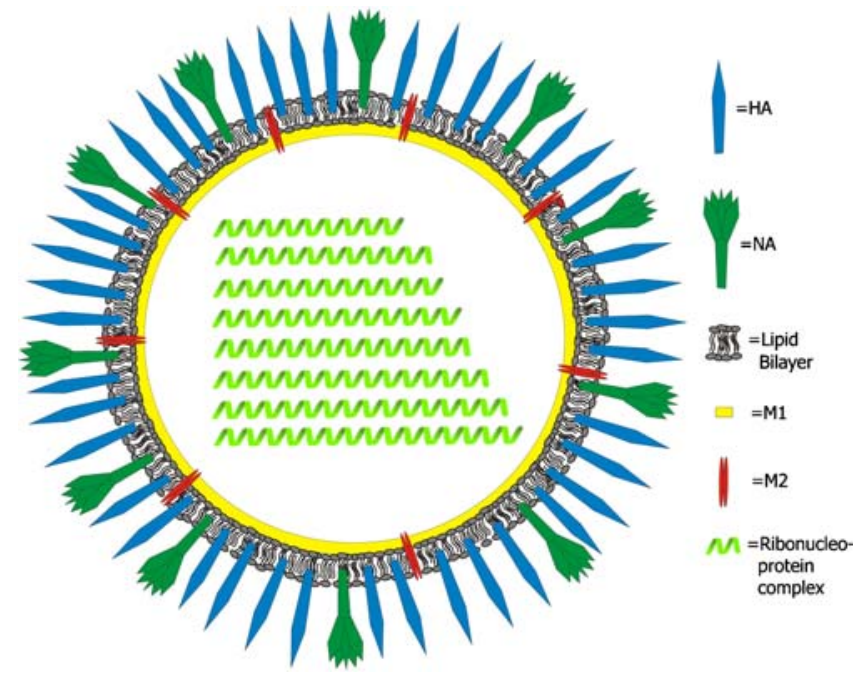

Fig. 1. A schematic drawing of the influenza virus. 


\section{Monomer}

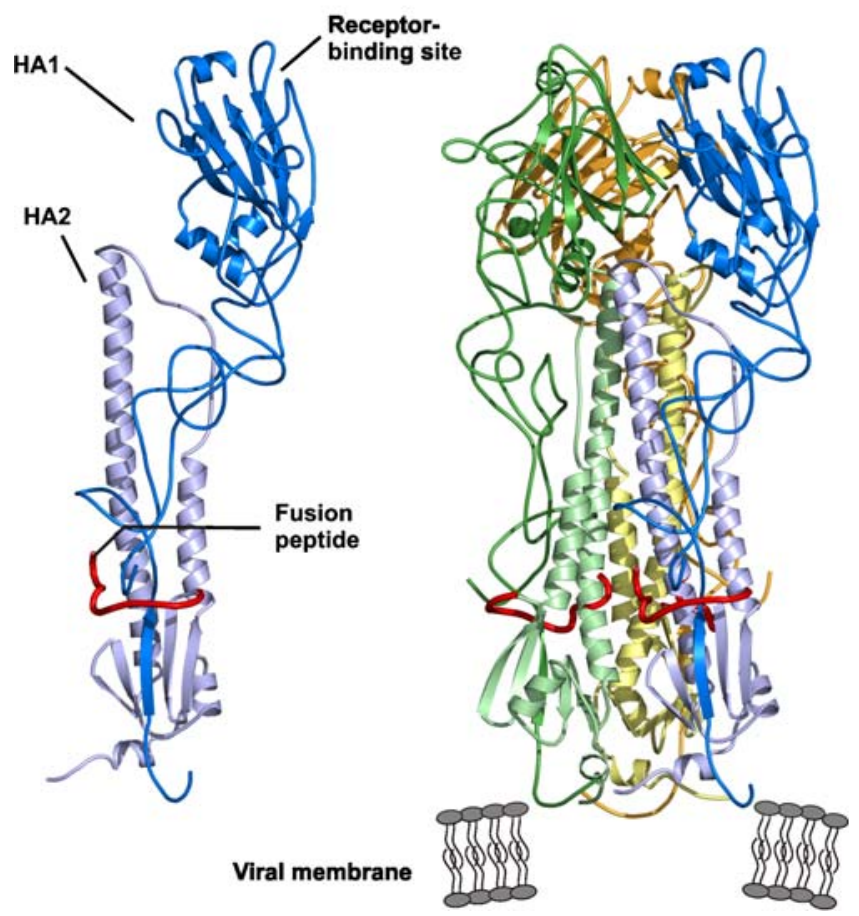

Fig. 2. The three-dimensional structure of the influenza HA. The HA monomer (left) and trimer (right). This figure was produced by André van Eerde (University of Groningen), using MOLSCRIPT, on basis of the co-ordinate file from the Protein Data Bank, code 3HMG.

disulfide bridges. The three monomers are assembled into a central $\alpha$-helical coiled-coil that forms the stem-like domain, and three globular heads containing sialic acid-binding sites. Each globular domain consists exclusively of HA1 folded in highly variable loops and eight antiparallel $\beta$-strands. The globular heads contain both the receptor binding sites and the antigenic epitopes $(11,12)$. NA is a tetrameric glycoprotein $(\sim 240 \mathrm{kD})$ consisting of a hydrophobic stalk and a globular head that contains the enzymatic and antigenic sites $(11,12)$. NA cleaves sialic acid and plays an important role in transport of the virus particles through the mucin layer lining the respiratory tract and also mediates the release of newly assembled virus particles $(11,12)$.

\section{Antigenic Drift and Shift}

Antigenically altered influenza strains are constantly formed by amino acid changes in the surface proteins, in particular HA. RNA replication lacks proof-reading mechanisms and influenza virus are therefore unable to repair polymerase errors that occur during RNA-replication. Within the viral genome mutations accumulate, resulting in replacement of the existing by a new antigenic variant. Mutations are seen in each of the gene products of the virus, but are most pronounced in the surface protein HA. As a result of these changes new influenza strains are constantly formed, that result in yearly arising epidemics. The mechanism of acquiring new influenza strains by mutations in HA is known as antigenic drift.
In contrast to the antigenic drift, that occurs constantly, antigenic shift occurs at irregular intervals and is defined as the introduction of a new influenza A subtype into the human population. Antigenic shift may be the result of either direct transfer of a new avian influenza virus to humans or reassortment between a human and avian virus, possibly in an intermediate host such as the pig (13). Aquatic birds are the natural reservoir of all known subtypes of the influenza A virus. These birds are highly mobile and are known to carry viruses over great distances. In addition, they transfer viruses to other birds via the excretion of large quantities of virus in their faeces. While often remaining healthy these birds form a mobile pool from which intermediate hosts can be infected with avian influenza virus. In these intermediate hosts reassortment between human and avian viruses may occur, resulting in new influenza strains that can infect and/or spread from person to person $(3,14)$. Recently, highly pathogenic avian influenza (HPAI) viruses have been shown to infect humans directly (zoonotic infection) without reassortment in an intermediate host.

Antigenic shift results in influenza pandemics which occur once in several decades. There have been three such pandemics in the twentieth century: in 1918, 1957, and 1968. At this moment a new highly pathogenic influenza subtype (H5N1) is circulating in birds. This virus has so far infected 340 humans of whom 209 died (WHO, 18 Dec. 2007). These cases are mainly found in South-East Asia. This new HPAI subtype, which is able to infect humans but can not (yet) spread between humans, forms a significant risk-factor for a new pandemic (14). It is possible that an avian influenza virus changes, so that it is able to infect humans and to easily spread from person to person. Because such a virus has not circulated among humans before, there is no immune protection in the human population (15). Consequently, an influenza pandemic may arise $(16,17)$.

\section{INFLUENZA VACCINES}

The currently used vaccines are mainly inactivated formulations containing at least the two viral surface antigens, HA and NA. There are four different types of inactivated influenza vaccines: whole inactivated influenza vaccines, split, subunit and virosomal influenza vaccines (Fig. 3). Also a live attenuated influenza vaccine is on the market (18-20). The seasonal vaccines are trivalent, containing the antigens from two subtypes of influenza A and one subtype of influenza B as recommended by the World Health Organization (WHO). To ensure an antigenic match with new circulating influenza viruses, the composition of these trivalent vaccines is updated, on the basis of WHO's worldwide surveillance of new influenza strains twice a year. Following vaccination with influenza A, around $90 \%$ of normal subjects achieve serum haemagglutination inhibition (HI) titers higher than 40, a level generally associated with a $50 \%$ reduced chance of contracting influenza. Implemented criteria for vaccine immunogenicity are based on the induction of an adequate level of virus-neutralizing antibodies (21).

The influenza virus for vaccine production is generally produced by propagation of virus in embryonated hen's eggs, although recent developments include vaccine virus production in cultured cells, such as Madin-Darby canine kidney 

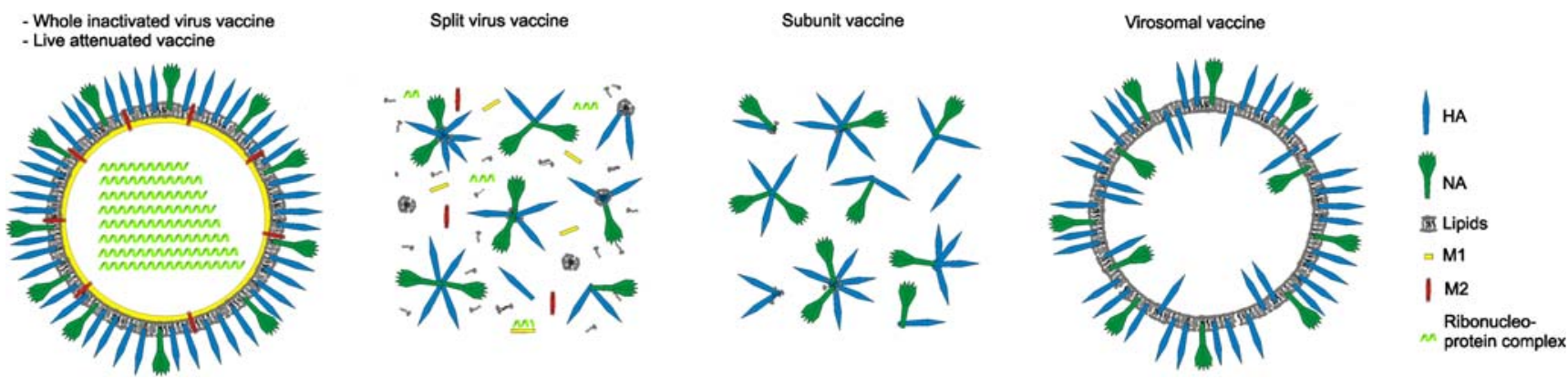

Fig. 3. Schematic drawings of WIV, split, subunit and virosomal vaccine.

(MDCK), Vero cells (derived from apenies embryonic lung fibroblasts) or Per.C6 cells (human fetal retinoblast immortalized by transfection with an E1 minigene of adenovirus type 5) (22-25). The virus (in allantoic fluid or medium) is harvested, concentrated and purified. The virus is subsequently inactivated with formaldehyde or $\beta$-propiolactone and processed to the vaccine type of choice.

\section{Whole Inactivated Virus Vaccine}

Whole inactivated virus (WIV; Fig. 3) vaccines contain inactivated influenza virus particles (virions) retaining the receptor binding and membrane fusion activity of the native virus. These vaccines contain all the components of the active virus and have the same physical structure as the active virus. However, no replication occurs, since replication is blocked due to modified nucleic bases (mainly purines) in the viral genome caused by the virus-inactivation step with formaldehyde or $\beta$-propiolactone (26).

Vaccination with WIV activates both the humoral and cellular arm of the adaptive immune response and WIV has been shown to be more immunogenic than split or subunit vaccines (4,27-31). The activation of the cellular arm of the adaptive immune system is probably caused by virtue of their particle-like structure and membrane fusion activity (21). Although cell-mediated immunity does not seem to contribute significantly in preventing infection, it plays a role in the recovery from influenza infection and may prevent influenzaassociated complications (4). Besides the fact that WIV vaccines are highly immunogenic, they are expected to induce more subtype cross-reactive cellular responses directed against conserved epitopes in internal influenza proteins (4,32-34). A disadvantage of WIV vaccines, in comparison with split or subunit formulations, is that they are associated with more frequent adverse effects, like pain and redness at the injection site or fever. Therefore, WIV vaccines are less suitable for the use among young children. The current use of WIV vaccines is limited and in many countries they are not licensed (35). However, WIV is regarded as a promising candidate pandemic vaccine (36).

\section{Split/Subunit Vaccine}

Today, most inactivated influenza vaccines are supplied as split vaccines, produced from chemically disrupted influenza virus, or as subunit vaccines containing predominantly purified HA and NA (Fig. 3). Millions of doses of these influenza vaccines are administered by intramuscular or subcutaneous injection throughout the world each year.
These vaccines trigger the humoral immune system resulting in the production of serum antibodies directed against HA and NA. These serum antibodies play a role in both resistance to and recovery from influenza infection (4). The overall rate of adverse reactions to split or subunit vaccine is low. As a result the use of split or subunit preparations is first choice in children younger than 9 years. However, as pandemic vaccine for the H5N1 subtype, non-adjuvanted split and subunit formulations appear to be poorly immunogenic (36).

\section{Virosomal Vaccines}

A relatively novel class of inactivated influenza vaccines is the virosomal influenza vaccine. Virosomes are virus-like particles, consisting of reconstituted influenza virus envelopes, which do not contain the genetic material of the native virus (Fig. 3) (21). Virosomes are produced from solubilized and subsequently reconstituted membranes of influenza virus (37-39). If produced properly, reconstituted virosomes retain the HA-mediated cell binding and membrane fusion properties of the native virus. As a result virosomes, like WIV, possess the functional characteristics, such as the particle-like structure, repetitive arrangement of the antigens on the virosomal surface and the fusion activity, which may induce enhanced immunogenicity (21). As a result, virosomes induce both virus-neutralizing antibody titers and prime the cellular arm of the immune system.

Recently commercial virosomal influenza vaccines have become available under the trade names Inflexal $\mathrm{V}^{\circledR}$ and Invivac $^{\circledR}$. Compared to conventional inactivated subunit influenza vaccine, local reactions at the site of injection (e.g. pain, swelling) are reported at a lower frequency with virosomal vaccines, whereas the reporting rates of systemic side effects (e.g. fever, headache) are comparable between the two vaccine types $(40,41)$.

\section{Live Attenuated Influenza Vaccines}

Besides the inactivated vaccines, also a live attenuated influenza vaccine (LAIV; Fig. 3), such as the recently in the USA authorized Flumist $^{\circledR}$, are on the market $(19,20)$ In contrast to the inactivated influenza vaccines which are administered by intramuscular or subcutaneous injection, LAIV is administered intranasally $(0.25 \mathrm{ml}$ in each nostril). Administration of LAIV is preformed via a spray device that produces aerosols with large droplets which are deposited in the nasopharynx (19). Flumist ${ }^{\circledR}$ contains the genes encoding the six internal segments from an attenuated donor strain 
(PB1, PB2, PA, M, NP and NS) and the two surface proteingenes (HA and NA) from the wild-type virus. The donor strain is cold-adapted (ca) and as such capable to grow in human nasal cavities $\left( \pm 32^{\circ} \mathrm{C}\right)$ but not in internal organs such as the lungs $\left(>37^{\circ} \mathrm{C}\right)(19)$. The underlying idea of vaccination with LAIV via the upper respiratory tract (nose) is to induce a secretory and systemic immune response that more closely resembles the immune response observed after natural infection. LAIVs induce a broad mucosal and systemic immune response. This in contrast to the current inactivated influenza vaccines, which only stimulate the systemic but not the mucosal immune system (4). On the other hand, LAIV nasal vaccines and inactivated i.m. vaccines are found to have similar efficacy in preventing influenza illness from homologous virus infections $(42,43)$. Compared to injected inactivated influenza vaccines, LAIVs are believed to provide broader immunity against circulating heterologous virus strains. The feature of LAIV virus to replicate and the possibility to prime the immune system of naive persons, may result in a vaccine that is more immunogenic in young children than inactivated vaccines (4). To date, it is unclear whether LAIV vaccines are also safe in immunocompromised patients (4).

\section{RATIONALE FOR THE DEVELOPMENT OF STABILIZED VACCINE FORMULATIONS}

In the liquid state, the stability of influenza vaccine is limited. In general, the stability of new vaccine compositions is tested by the manufacturer in order to support regulatory filing and for GMP compliance. The stability is determined by investigation of the content of HA antigen, presence of NA, $\mathrm{pH}$, content of preservative (if applicable) and appearance. The shelf-life of the product is based on the most sensitive parameter, in general the HA content (HA potency)(44). Stability studies are generally performed according to $\mathrm{ICH}$ guidelines $(45,46)$. Stability depends among others on vaccine strain (47), $\mathrm{pH}$, addition of stabilizers such as gelatin or polysorbate, compatibility of the product with container and closure and treatments needed to reduce adsorption or interaction with the container (44). Most inactivated influenza vaccines are stable for about 1 year in the refrigerator $\left(2\right.$ to $\left.8^{\circ} \mathrm{C}\right)$. In contrast to inactivated influenza vaccines, LAIV must be stored frozen $\left(-15^{\circ} \mathrm{C}\right.$ to $\left.-25^{\circ} \mathrm{C}\right)$. To overcome the freezing stresses, the vaccine is stabilized with phosphate glutamate buffer, containing sucrose. Before use the vaccine must be thawed (for up to $60 \mathrm{~h}$ at 2 to $8^{\circ} \mathrm{C}$ ) and should not be refrozen. However, a refrigerator stable formulation is in development $(44,48)$.

\section{Cold Chain}

Inactivated influenza vaccines are temperature-sensitive and must be stored at 2 to $8^{\circ} \mathrm{C}$. Elevated temperatures can cause inactivation of the vaccine antigens, while temperatures below freezing result in formation of ice and concentration of solutes that may cause denaturation of the antigen $(47,49$, 50). Because high as well as low temperatures can be detrimental, influenza vaccines have to be stored within a narrow temperature range. This narrow temperature range makes the process of distribution and storage complicated, vulnerable and costly. Although it has been demonstrated that the influenza subunit vaccine can be stored for a couple of days outside the refrigerator at room temperature (47), vaccine distribution remains one of the greatest risk for vaccine quality, especially when the vaccine leaves the central storage depots. During transport and storage at the local level the risk of storage outside the temperature range $\left(2-8^{\circ} \mathrm{C}\right)$ increases. Freeze-sensitive vaccines are still shipped with frozen ice packs and/or improperly conditioned ice packs pose the risk that the vaccine will be exposed to freezing temperatures. Improper storage is not easily detected. In certain cases damage (especially aggregation) induced by heat or freezing can be detected visually (Fig. 4), with or without a shake-test. However, in many cases no clear visual changes are observed (51). Time-temperature indicators, vaccine vial monitors (VVMs) can prevent usage of vaccines that were stored too long at elevated temperatures. An influenza vaccine formulation that would be stable at room temperature, or even somewhat higher temperatures (up to $35^{\circ} \mathrm{C}$ ), and be insensitive to freezing stresses, would reduce the dependency on cold-chain facilities. Such a vaccine would considerably simplify vaccine distribution and enable the integration of vaccine logistics with general drug distribution, especially in developing countries. Moreover, this would reduce vaccine losses. Both aspects would result in enormous annual cost savings.

\section{Stock Piling}

Recent outbreaks of HPAI virus infections in poultry have raised concerns that a new influenza pandemic might occur in the near future. The key preventive method to protect the population against a pandemic virus is an influenza vaccine (52). In the most extreme scenario, adequate pandemic preparedness would demand the avail-

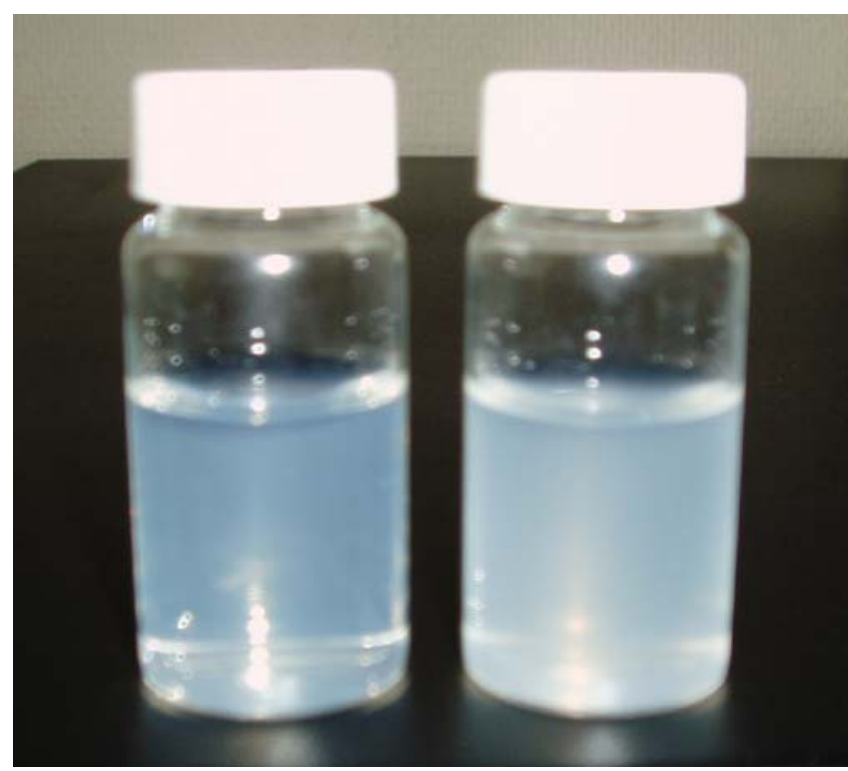

Fig. 4. Visual observation of freeze-induced damage caused by accidental storage below $0^{\circ} \mathrm{C}$. The left bottle contains the original subunit vaccine. The right bottle contains the freeze-damaged subunit vaccine. The freeze-thaw cycle resulted in a turbid, less opalescent vaccine solution. 
ability of 13 billion doses of vaccine (two doses for 6.5 billion people) to vaccinate the entire world population. However, today's global production capacity for a trivalent influenza vaccine is around 300 million doses per year and the time needed until the first vaccine dose can be used is at least 4 months $(10,53)$. As a result the WHO has encouraged individual countries to produce a pandemic preparedness plan. Such a plan would guarantee fair distribution of vaccine and pre-organized vaccine supply in a clearly defined manner.

A new feature discussed in the context of pandemic preparedness is stockpiling of vaccine from different influenza A virus strains (e.g. H5, H7 and $\mathrm{H} 9$ ) assuring immediate availability (52,53). Although such vaccines may not be a perfect match to a newly emerging influenza A virus variant, a certain degree of intra-subtypic immunity and immunological priming is expected to ameliorate the effects of an initial pandemic wave. Current seasonal (inactivated) influenza vaccines have a shelf-life claim of 1 year only. In contrast, stable vaccine formulations of the $\mathrm{H} 1-\mathrm{H} 16$ subtypes would not only reduce the dependency on the cold chain, but could also increase the shelf-life of stockpiled vaccines considerably. As a result such a stable vaccine formulation would facilitate stockpiling of potential vaccines against epidemic and pandemic viruses. Consequently, this would provide in immediately available and readily distributable vaccine in a pandemic situation.

\section{Non-parenteral Dosage Forms}

For mass vaccination against influenza, especially in case of a pandemic, the use of a non-parenteral influenza vaccine might be preferable for several reasons. Non-parenteral administration, simplifies the logistics of immunization and improves the immunization coverage as has been shown by the success of the oral polio vaccine (54). The ease of use and cheap administration of the oral (live) polio vaccine in vaccination programs, contributed to the successful worldwide polio reduction. Non-parenteral dosage forms would make administration of influenza vaccines safer during vaccination programs, since iatrogenic infections due to needle-stick injuries or the use of unsterile needles, which are especially a high risk in third-world countries, cannot occur $(6,55)$.

In addition, it has been shown that administration of influenza vaccines via non-parenteral routes like the nasal, oral or pulmonary route has the potential to induce and to promote mucosal and systemic humoral as well as cellmediated immune responses. In contrast to parenteral vaccination, mucosal vaccination has the potential to induce secretory $\operatorname{IgA}$ antibody responses in the respiratory tract and the oropharyngeal region. Since mucosal IgA responses have been shown to exhibit cross-protective immunity against antigenically distinct viruses $(56,57)$, these vaccinations might give protection not only against homologous virus, but also against drifted, heterologous strains.

In the development of new needle-free dosage forms, dried influenza vaccine formulations offer not only the opportunity of a more stable product, but also facilitate new or improved targeting strategies of the vaccine compound. State of the art technologies, like formulation technologies (tablets with dried vaccine incorporated and supplied with special coatings; powders designed for nasal or pulmonary delivery) and the use of special designed delivery devices might enable efficient targeting of the vaccine to specific sites in the human body. Consequently, the immediate or sustained release and/or increased residence time of the vaccine compound at the desired place might result in improved immune responses.

\section{METHODOLOGIES FOR STABILIZATION OF INFLUENZA VACCINES}

The most commonly used method to stabilize biologically active macromolecules, such as proteins, vaccines and gene delivery systems, is to convert them to dry powders. In general biopharmaceuticals are more stable in the solid state than in the liquid state. This is believed to be related to the reduced mobility of the biopharmaceutical and the absence or reduction of certain degradation pathways such as hydrolysis. However, depending on the drying method, freezing and/or drying stresses may affect the structural integrity and thereby activity of the biopharmaceutical. Accordingly, appropriate stabilizers are required for preservation of these properties. It is well known that sugars can stabilize proteins (58-63), liposomes, lipoplexes (64-69) and various viruses (70-73) during drying and subsequent storage. If dried properly, the active substance, complex or vesicle is incorporated in a matrix consisting of amorphous sugar in its glass state. The stabilizing effect of these sugar glasses has been explained by the formation of a sugar matrix which acts as a physical barrier between particles (particle isolation) and strongly reduces diffusion and molecular mobility (vitrification). Both the physical barrier (74) and the lack of mobility provided by the glass matrix (75), prevent aggregation and degradation of the biopharmaceutical. Moreover, during the drying process, the sugar replaces the water molecules in the hydrogen-bonding interaction with the active material, such that the structural integrity of the drug is preserved (76). Under dry conditions, the glass matrix is maintained as long as the temperature is kept well below the glass transition temperature $\left(T_{\mathrm{g}}\right)$, which is characteristic for the stabilizing sugar used.

Potentially there are several different drying methods that can be used to convert the liquid influenza vaccine (with the required excipients) into a stable powder. Each of the methods has typical advantages as well as drawbacks, of which the relevance and magnitude are further determined by the applied process conditions as well as the formulation (excipients used). A number of aspects determine the suitability of a specific drying method. Most important in this respect are process stresses, crystallization risk, process speed, ease to design particles, capacity, recovery, costs and current (industrial) experience.

In the past decades several papers have been published in which dried influenza vaccines were used. Most of these dried influenza vaccines were produced in order to facilitate new needle-free dosage forms for nasal, pulmonary or epidermal delivery. The integrity and stability of the influenza vaccine compound after drying has been examined in only a limited number of the published articles. From these studies it is difficult to draw definitive conclusions with regard to the influences of process and formulation parameters on vaccine integrity and stability. However, it is possible to extrapolate 
notions described in the literature concerning drying of biopharmaceuticals. In the proceeding paragraphs an overview of the suitability of the major drying methods for influenza vaccines will be given based on general concepts concerning drying of biopharmaceuticals (as summarized in Table I) and the few dried influenza vaccines described in literature (as summarized in Table II).

\section{Freeze Drying and Spray-Freeze Drying}

\section{The Process}

Generally, freeze-drying (lyophilization) is the preferred drying method for biopharmaceuticals (89). Freeze-drying is a process by which the material is frozen and subsequently dried by the removal of water by sublimation (directly from the solid phase to gas) under reduced pressure. As stated above, for successful drying of biopharmaceuticals a stabilizer, such as a sugar is needed to protect the biopharmaceutical both during drying and subsequent storage.

The principle of sugar glass production by lyophilization is illustrated by the state-diagram of a binary sugar/water system presented in Fig. 5. The figure is illustrative for the process by which a biopharmaceutical is incorporated in a glassy matrix of sugar using lyophilization. However, for the sake of clarity the contributions of the biopharmaceutical and compounds such as buffers and salts are neglected in the state diagram.

Upon cooling of a sugar solution of composition $\mathrm{A}$, water starts to crystallize below $0^{\circ} \mathrm{C}$ (point B) due to freeze point depression caused by the solute. During freezing, the crystallization temperature gradually decreases because the remaining solution becomes more concentrated. At the eutectic temperature ( $T_{\mathrm{e}}$, point $\mathrm{C}$ ) the sugar should start to crystallize simultaneously with the water molecules if the solution would be in thermodynamic equilibrium. However, when the solution is rapidly frozen, e.g. in liquid nitrogen or dry ice, the crystallization rate is too low for the sugar to form crystals. As a consequence, rapid cooling below the $T_{e}$ results in further crystallization of water only and so-called freeze concentration of the sugar continues. At the glass-transition temperature of the maximally freeze-concentrated fraction $\left(T_{g}^{\prime}\right.$, point $\left.\mathrm{D}\right)$, the viscosity increases dramatically resulting in immobilization of the sugar and water (and further components), and a glass is formed. In this glass the sugar molecules are randomly orientated (amorphous state) and form a vitrified matrix in which water and biopharmaceutical are captured. Due to the high viscosity of the amorphous matrix also water molecules are not able to crystallize anymore.
Consequently, the composition of the glass remains the same upon further cooling $(\mathrm{D} \rightarrow \mathrm{E})$.

To obtain the biopharmaceutical in a dry amorphous glass, the frozen sample is kept under vacuum and water is removed by sublimation. During primary drying, the first stage of the freeze drying process, the ice formed during freezing of the sample is removed. The temperature during this primary drying must be kept below the $T_{g}^{\prime}$. This is essential because above this temperature the sugar glass turns into the rubbery state in which the molecular mobility is considerably increased and crystallization of the sugar or phase separation may occur. This is detrimental for the stabilization of the incorporated biopharmaceutical compound since hydrogen bonds or other stabilizing interactions with the sugar are lost and the translational freedom of the biopharmaceutical increases, which could cause aggregation. In addition, the mechanical forces induced by crystallization of the sugar may damage the structure of the biopharmaceutical compound, which in turn may lose functional activity.

The remaining water molecules captured in the glassy matrix upon rapid cooling are removed during the secondary drying when the glass surface is free of ice. During this secondary drying the temperature can be slowly increased as long as the temperature is below the $T_{\mathrm{g}}$ of the watercontaining product $(\mathrm{E} \rightarrow \mathrm{F})$. After removal of all water, the biopharmaceutical compound is incorporated in a dry sugar glass with a $T_{\mathrm{g}}$ depending on the sugar used. To assure a long shelf-life, the dry formulation should be stored well below its $T_{\mathrm{g}}$ to avoid transition into the rubbery state (which could result in crystallization). Moreover, generally a highly porous cake with a high specific surface area is obtained after lyophilization, which can be easily reconstituted. However, this porous cake also easily absorbs water. As a result the product should be kept at a low relative humidity (adequate packaging required), since absorbed water decreases the $T_{\mathrm{g}}$ of the formulation (see glass transition curve as function of water content).

Spray-freeze drying (SFD) is a relative new drying process to produce biopharmaceutical powders that combines atomization, generating a cloud of small droplets (leading to rapid freezing), and lyophilization. The state-diagram of incorporation of a biopharmaceutical in a glassy matrix of sugar by SFD is the same as that of conventional lyophilization (Fig. 5). A liquid solution containing a biopharmaceutical compound and stabilizer(s) is atomized into a cryogenic medium, in general liquid nitrogen, to vitrify the droplets $(\mathrm{A} \rightarrow \mathrm{E})$, followed by removal of ice and water molecules captured in the glassy matrix by lyophilization $(\mathrm{E} \rightarrow \mathrm{F})$. A main advantage of SFD over normal freeze drying is the

Table I. General Concepts Concerning Drying of Biopharmaceuticals

\begin{tabular}{|c|c|c|c|c|c|c|c|c|c|}
\hline & $\begin{array}{l}\text { Atomization } \\
\text { Stress }\end{array}$ & $\begin{array}{l}\text { Freezing } \\
\text { Stress }\end{array}$ & $\begin{array}{l}\text { Heating } \\
\text { Stress }\end{array}$ & $\begin{array}{l}\text { Process } \\
\text { Speed }\end{array}$ & $\begin{array}{l}\text { Crystallization } \\
\text { Risk }\end{array}$ & $\begin{array}{l}\text { Particle } \\
\text { Design }\end{array}$ & Capacity & Costs & $\begin{array}{l}\text { Industrial } \\
\text { Experience }\end{array}$ \\
\hline Freeze drying & + & - & + & - & + & - & \pm & - & + \\
\hline Spray-freeze drying & - & + & + & \pm & + & + & \pm & - & - \\
\hline Spray drying & - & + & - & + & - & + & + & + & + \\
\hline Vacuum drying & + & + & \pm & - & - & - & \pm & + & + \\
\hline Supercritical fluid drying & - & + & \pm & + & \pm & + & + & - & - \\
\hline
\end{tabular}

+, Favorable; -, Unfavorable 


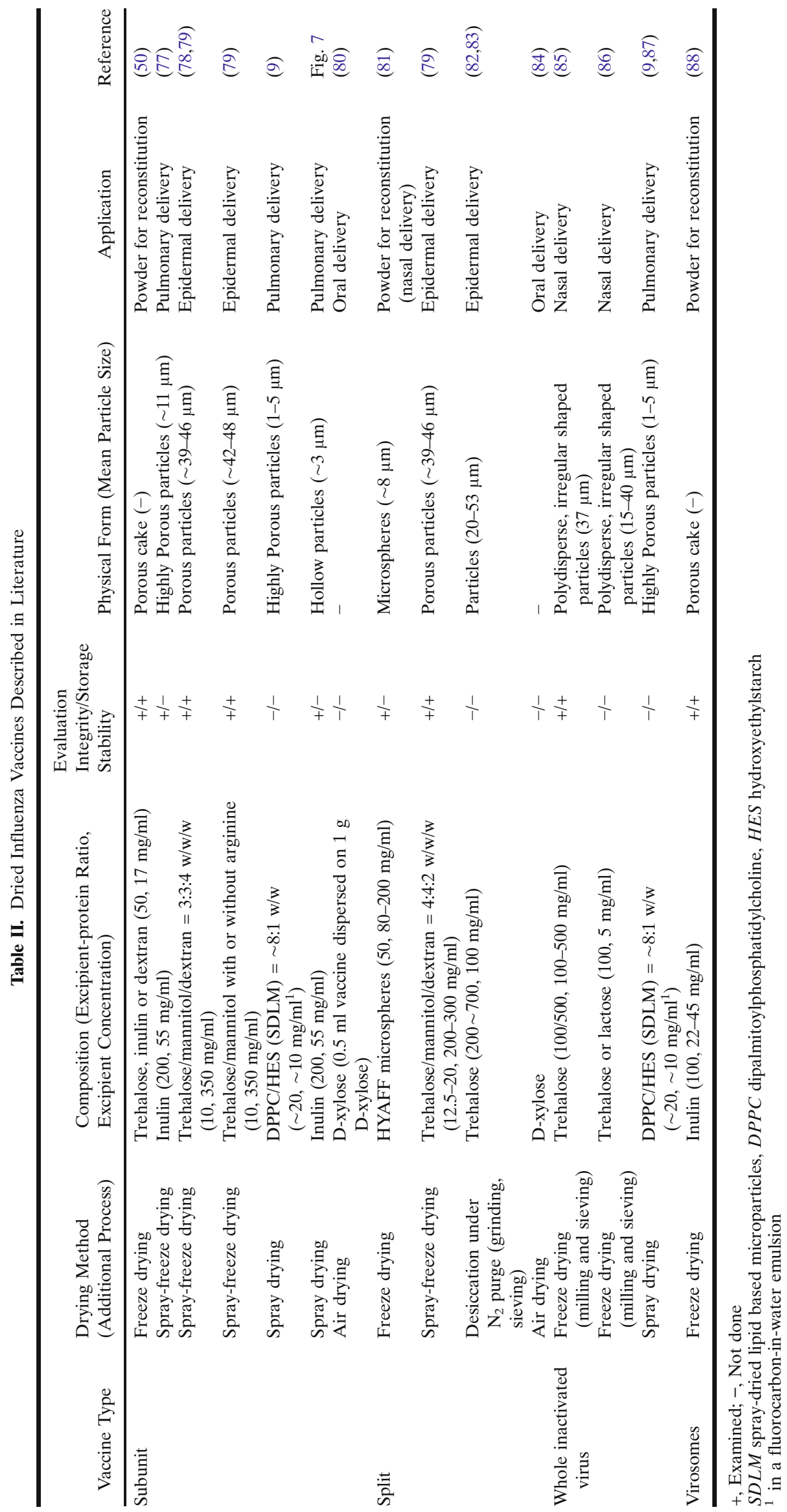




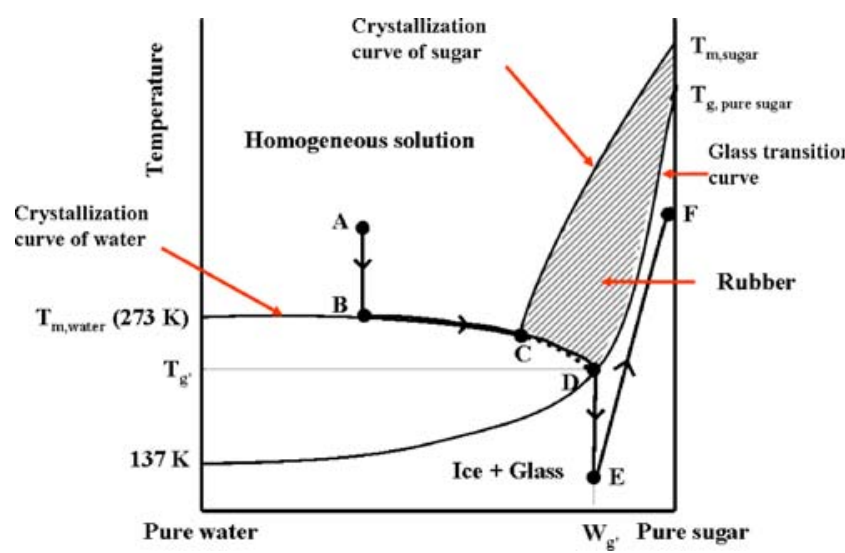

Fig. 5. Lyophilization - state-diagram of a binary sugar/water system and the incorporation of a biopharmaceutical in a glassy matrix of sugar [freezing $(\mathrm{A} \rightarrow \mathrm{E})$ and drying $(\mathrm{E} \rightarrow \mathrm{F})]: A$, starting composition; $B$, point where freezing of water starts; $C$, eutectic point $\left(T_{\mathrm{e}}\right) ; D$, maximally freeze concentrated fraction at its glass temperature $\left(T_{g}^{\prime}\right)$; $E$, maximally freeze concentrated fraction below its glass temperature $\left(T_{g}^{\prime}\right) ; F$, lyophilized formulation.

extremely rapid vitrification (fast $\mathrm{A} \rightarrow \mathrm{E}$ traject) due to the enormous surface area for heat (energy) transfer generated during the atomization (the spraying process) and a direct contact of the liquid droplets with the freezing medium. This is important since rapid vitrification prevents phase separation. Moreover, the large surface area allows rapid drying. Another advantage of SFD is the capability to produce particles with adjustable sizes which can be used for certain drug delivery strategies such as epidermal powder delivery and dry powder inhalation.

Lyophilization and SFD are not processes without concerns. Typically, freezing and drying pose stress on the compounds involved. In response to freezing, multiple ice crystals of various sizes grow and interact with the freezeconcentrated fraction (the highly viscous fluid phase containing non-crystalline components and the remaining non-frozen water). During this process, a large ice/liquid interface is created that presents a surface area for protein adsorption. This may result in conformational changes and disruption of the vaccine compound. Moreover, the solute concentration of the nonfrozen fraction increases during freezing, resulting in acceleration of reaction kinetics (90) and changed physical properties such as ionic strength and relative composition of the solution, which may further destabilize the vaccine $(89,91)$.

In the development of lyophilized biopharmaceuticals, the choice of buffer type can be of major importance $(50,89$, 92). Phosphate-buffered saline (PBS) is an often used buffer. However, due to crystallization of sodium or potassium dibasic phosphate, the $\mathrm{pH}$ of the PBS formulation shows a downshift during freezing. When the biopharmaceutical is sensitive for $\mathrm{pH}$ changes this shift may lead to destabilization or inactivation of the compound $(50,89,92)$. Buffer systems composed of organic molecules generally do not induce $\mathrm{pH}$ change during freezing. However, the $T_{g}^{\prime}$ and the $T_{\mathrm{g}}$ can be strongly lowered by them (92).

In the case of SFD, air-water interfacial stresses and shear stresses induced by the atomization of the feed solution may lead to destabilization of the compound. Biopharmaceuticals, vaccine compounds such as HA, NA and lipids, being amphiphilic membrane components are surface-active. As a result, the compounds tend to adsorb at the air-water interface (the fine droplets have a high specific surface area) where the large surface free energy may cause the biopharmaceutical to be disrupted and to expose its hydrophobic regions resulting in aggregation (93).

Besides the risk of losing the structural integrity of the biopharmaceutical during the drying process, other disadvantages of lyophilization are the long process time and the high energy costs.

\section{Freeze Drying and Spray-Freeze Drying of Influenza Vaccine}

Freeze drying and spray-freeze drying have been used for drying of various influenza vaccine formulations (Table II). Subunit and split vaccines have been successfully (spray-) freeze dried with conservation of the antigen's molecular structure, potency and/or antigenicity in mice (50,77-79).

However, during lyophilization various process factors can affect the integrity of the vaccine compound. HA in influenza subunit vaccine is susceptible to freezing stresses, when no stabilizers are used, especially at low freezing rates $(49,50)$. However, it has been shown that sugars (trehalose, inulin and dextran) can prevent freeze-induced damage (50). They revealed with tryptophan fluorescence spectroscopy, circular dichroism spectroscopy and a proteolytic assay, that changes in secondary and tertiary structure of HA caused by freezing were absent when sugars were added before freezing.

In the development of lyophilized influenza vaccines the choice of buffer type has been shown to be of major importance (50). By nature, HA within the influenza virus possesses a spring-loaded conformation that changes upon acidification in the endosome $(\mathrm{pH} / 5)$ in order to mediate fusion of the virus with the endosomal membrane. As a result $\mathrm{HA}$ is sensitive to the $\mathrm{pH}$ drop during freezing, when PBS is used as buffer. The irreversible conformational changes of HA during freezing can be prevented by the use of another buffer, Hepes buffered saline (HBS), which does not show strong $\mathrm{pH}$ changes during freezing (50). Moreover, a fast freezing rate and the use of sugars, like trehalose, inulin or dextran, are aspects that may contribute to the successful production of vaccine powder with conservation of the structure of HA (50).

Maa et al. produced a vaccine powder of a trivalent split vaccine by SFD using combinations of carbohydrates. They found that combinations of trehalose, mannitol and dextran at different concentrations $(20-30 \% \mathrm{w} / \mathrm{v})$ were capable to preserve during SFD the antigen's potency as well as immunogenicity in vivo (79).

WIV vaccine has been successfully lyophilized by Huang et al.. They lyophilized a mixture of WIV and trehalose in a ratio of 1:500 (10 $\mu \mathrm{g}$ virus/5 $\mathrm{mg}$ trehalose) from sterile saline. After lyophilization, subsequent milling and reconstitution the whole virions retained their haemagglutination capacity with chicken erythrocytes (85).

Influenza virosomes were lyophilized by De Jonge et al. $(88,94)$. Virosomes $(225-450 \mu \mathrm{g} / \mathrm{ml})$ prepared from $\mathrm{A} /$ Panama virus were lyophilized with inulin $1.8 \mathrm{kD}(22.5-$ $45 \mathrm{mg} / \mathrm{ml})$ in a ratio of 1:100 $(w / w)$. These lyophilized virosomes retained their fusogenic properties in vitro and 
antigenicity in mice. In contrast, lyophilization of virosomes without protectant resulted in reduced fusogenic properties and disruption of the vesicular structure of the virosomes.

\section{Spray Drying}

\section{The Process}

Spray drying is the process of drying a liquid feed into dry particles through atomization of the feed (generating a cloud of small droplets) into a hot drying gas. Usually air is used, but sensitive materials and solvents like ethanol may require oxygen-free drying with nitrogen gas instead. Spray drying can be used for biopharmaceuticals. The incorporation of a biopharmaceutical in a glassy matrix of sugar by spray drying is illustrated by the state-diagram of a binary sugar/ water system presented in Fig. 6. The contribution of the biopharmaceutical is neglected, since it is usually present in low amounts. While with lyophilization the biopharmaceutical is rapidly vitrified by application of low temperatures, with spray drying the biopharmaceutical is rapidly vitrified by using a large liquid-gas interface at elevated temperature (a rapid moisture removal).

Spray drying starts with atomization of a sugar solution of composition A (and temperature A) in the hot air of the spray dryer. By atomizing the solution a cloud of droplets is created. Just after atomizing, the droplet surface is moisturesaturated and by the endothermal process of water evaporation the droplet temperature remains significantly lower than the hot air temperature. During evaporation of the water the remaining concentration of sugar in the droplet increases $(A \rightarrow B)$. Simultaneously the droplet temperature begins to rise $(A \rightarrow B)$ since water diffusion to the surface cannot keep the surface moisture-saturated, while due to the endothermic heat of evaporation the air temperature significantly decreases. At a certain concentration (point B) the sugar should become solid (e.g. by crystallization or amorphous precipitation) simultaneously with the evaporation of the water molecules under conditions that the solution is in thermodynamic equilib-

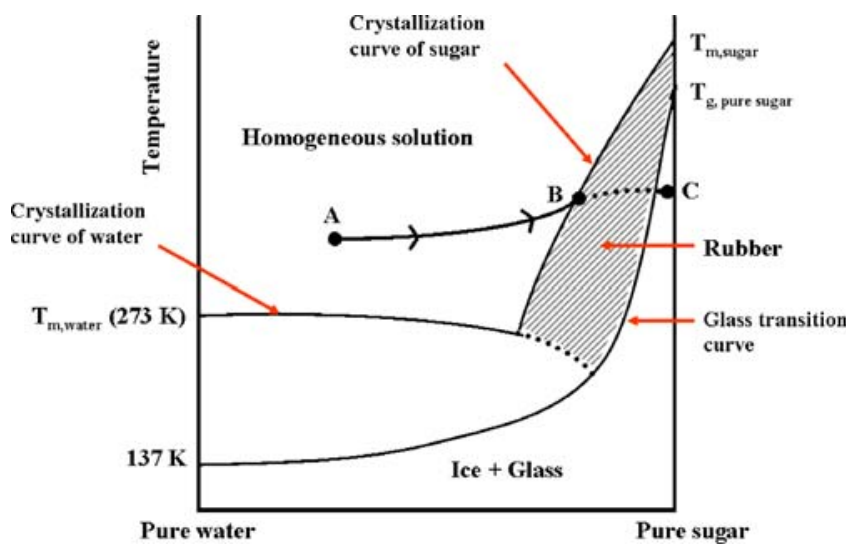

Fig. 6. Spray drying-state-diagram of a binary sugar/water system and the incorporation of a bio-pharmaceutical in a glassy matrix of sugar $(\mathrm{A} \rightarrow \mathrm{C}$, assuming a homogeneous composition within the droplets). $A$, starting composition; $B$, point where the sugar solution (in the droplets) passes the crystallization curve of sugar; $C$, spray dried product in the amorphous glassy state. rium. However, when the evaporation rate of water is fast enough, there is no sufficient time for the sugar to crystallize by which the solution will pass through the rubbery state $(B \rightarrow C)$ and turn into the dry amorphous glassy state.

Spray drying is not a process without concerns. Firstly, the biopharmaceutical may suffer from heat denaturation by hot air. Although the droplet temperature only increases marginally as a result of energy consumption during evaporation of water, it is wise to use process parameters that are well matched in order to assure that the outlet temperature is not too high thereby reducing the risk of denaturation/ degradation of the vaccine compound. Secondly, air-water interfacial stresses and shear stresses induced by the atomization of the feed solution, just as with SFD, may lead to degradation of the biopharmaceutical. Therefore, the addition of surface-active agents (surfactants) to the mixture before spray drying has been used to remove proteins from this interface and consequently improve their stability $(90,95,96)$.

Again the use of carbohydrates may prevent deterioration by increasing unfolding temperatures of the (proteinaceous) biopharmaceutical. Various sugars or polyols can be used for the spray drying of proteinaceous compounds. During spray drying mono- and disaccharides or small polyols with a low $T_{\mathrm{g}}$ have the tendency to crystallize resulting in degradation of the biopharmaceutical (95,97-99). However, formulations that crystallize less easily and have a high $T_{\mathrm{g}}$ can be made (100-103).

\section{Spray Drying of Influenza Vaccines}

Spray drying has been used to prepare dried influenza subunit and WIV vaccines. Recently, an influenza subunit vaccine powder was prepared by spray drying using the oligosaccharide inulin (inulin $4 \mathrm{kD}, T_{\mathrm{g}}$ of $156^{\circ} \mathrm{C}$ ). A solution of subunit vaccine (A/Panama $\mathrm{H} 3 \mathrm{~N} 2 ; 275 \mu \mathrm{g} / \mathrm{ml}$ ) and inulin $(55 \mathrm{mg} / \mathrm{ml})$ in PBS was spray dried using a Mini Spray Dryer. The vaccine powder obtained after spray drying consisted of spherical and smooth particles with an average particle size of $3 \mu \mathrm{m}$. Moreover, the process stresses did not have an adverse effect on the antigen's immunogenicity in vivo (unpublished results shown in Fig. 7).

Spray-dried lipid-based microparticles (SDLM) have been used to encapsulate subunit and WIV vaccine in microparticles in order to target APC in the respiratory tract $(9,87)$. Besides vaccine these microparticles contained lipidsurfactants, dipalmitoylphosphatidylcholine and distearoylphosphatidylcholine $(75-85 \% \mathrm{w} / \mathrm{w}$; both surfactants occur in the lung), and a polysaccharide, hydroxyethylstarch. The release of antigens (pharmaceutical availability) from these SDLMs was limited, but co-formulation with the biocompatible surfactant tyloxapol improved the immune profile of these particles (9). However, it is unclear whether the structural integrity of the vaccine compounds was affected by the drying process, since only a bioassay based on peptide recognition and SDS-treatment was used to determine the antigen content. In particular, due to their particulate nature, WIV but also virosomes may possess a higher sensitivity to shear stresses during atomization applied by spray (freeze) drying than subunit and split vaccines being proteinous vaccines. The bioassay used does not reveal whether the WIV particles are still intact after the drying process. 


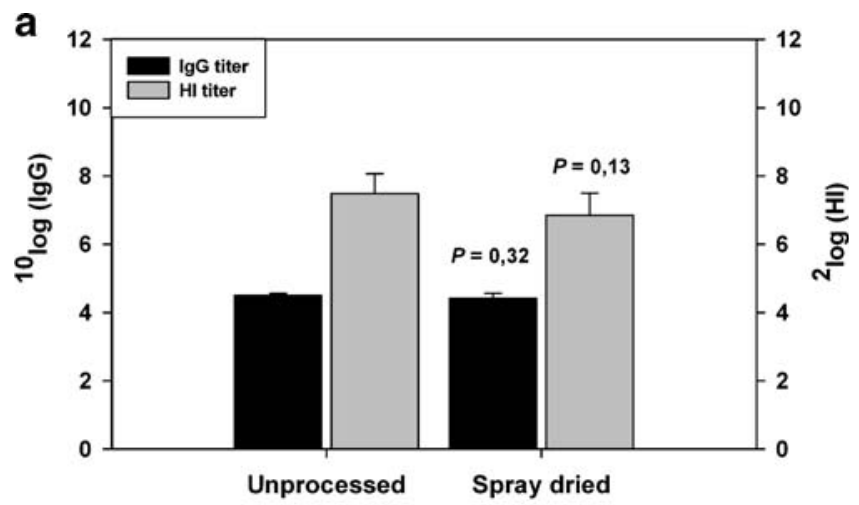

b

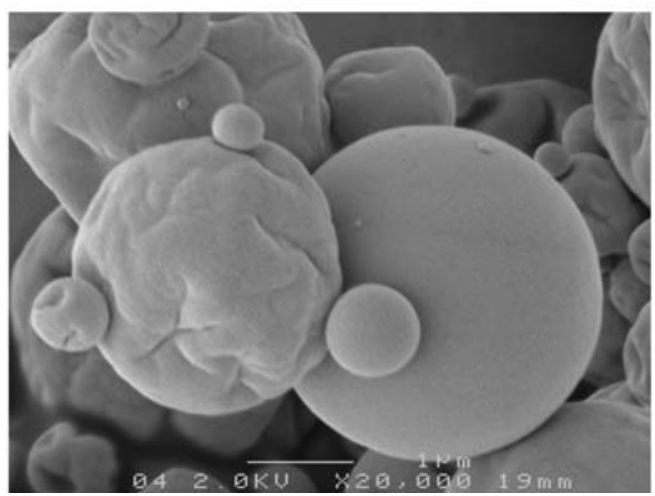

Fig. 7. Spray dried influenza subunit vaccine. The vaccine was dried with inulin as stabilizer, using a $5.5 \% \mathrm{w} / \mathrm{v}$ sugar solution at a ratio sugar/HA $=200 w / w$. a Vaccine antigenicity of spray dried influenza subunit vaccine. Subunit antigen-specific $\operatorname{IgG}$ serum titers (black bars) and serum HI titers (grey bars) in Balb/c mice. Animals were immunized i.m. (on days 0,14 and 28 ) with $5 \mu \mathrm{g}$ subunit antigen (A/ Panama) from unprocessed $(n=4)$ or reconstituted spray dried subunit vaccine $(n=8)$. On day 52 mice were sacrificed and titers were determined according to (49). The results are expressed as the geometric mean titer \pm standard deviation for each group. b Scanning Electron Micrograph of spray dried influenza vaccine particles. Magnification of $\times 20.000$, average particle size is $\sim 3 \mu \mathrm{m}$.

\section{Vacuum Drying and Desiccation}

\section{The Process}

Vacuum drying or vacuum evaporation is the process of drying at a pressure where the boiling point of water has been lowered to below the sample temperature. The incorporation of a biopharmaceutical in a glassy matrix of sugar by vacuum drying (and desiccation) is illustrated in Fig. 8.

A liquid solution of composition $\mathrm{A}$ is subjected to low pressure $\left(<3.17 \mathrm{kPa}\right.$ at $\left.25^{\circ} \mathrm{C}\right)$ and starts to boil. Constant addition of heat is necessary to prevent the sample to cool from heat loss by evaporation. At a certain point the sugar solution is saturated (point B); the sugar should start to precipitate simultaneously with the evaporation of the water molecules when the solution is in thermodynamic equilibrium. However, when the evaporation rate of water is fast enough, there is no sufficient time for sugar crystallization, by which the solution will pass through the rubbery state $(B \rightarrow C)$ and turn into the dry amorphous glassy state.

Desiccation is the process of drying using a hygroscopic substance (a desiccant) in a sealed container (desiccator).
During desiccation small amounts of material are dried on a shelf above a drying agent or desiccant, such as dry silica gel or anhydrous caustic soda. Just as vacuum drying this drying process is carried at room temperature or elevated temperatures.

In contrast to spray drying that proceeds very rapidly, vacuum drying and desiccation can take hours. As a result the risk of sugar crystallization and/or phase separation in the rubbery state increases. Moreover, during vacuum drying large-air-liquid interfaces are created by the boiling of the solution, which increases the risk of adsorption of the biopharmaceutical at this interface and subsequent denaturation. Despite these increased risks, it should be realized that these drying methods offer the opportunity to dry without heating or freezing stresses and can be performed at low costs.

\section{Vacuum Drying and Desiccation of Influenza Vaccines}

Air drying and desiccation have been used for preparing dry subunit and split influenza vaccines. In different laboratories, subunit vaccine has been air dried after dispersing $0.5 \mathrm{ml}$ vaccine on $1 \mathrm{~g}$ D-xylose $(80,84)$. Chen et al. prepared dried split vaccine powder by desiccation a vaccine in trehalose $(100 \mathrm{mg} / \mathrm{ml})$ solution overnight using an $\mathrm{N}_{2}$ purge $(82,83)$. Although these researchers performed immunization studies it was not investigated whether the integrity of the vaccine compound in their dried product was affected. The maintenance of the integrity of the vaccine compound is a concern with these specific drying techniques. As mentioned above, the long drying time increases the risk of phase separation and/or crystallization, especially when small polyols like D-xylose and trehalose are used (98,104-106).

\section{Supercritical Drying}

A relative new drying method is supercritical fluid (SCF) drying (reviewed in: (107) and (108)). Although until now no influenza vaccines have been dried by supercritical drying, supercritical drying is a drying method with considerable potential that has been successful applied for several biopharmaceuticals. Examples are Diphtheria toxoid and live-

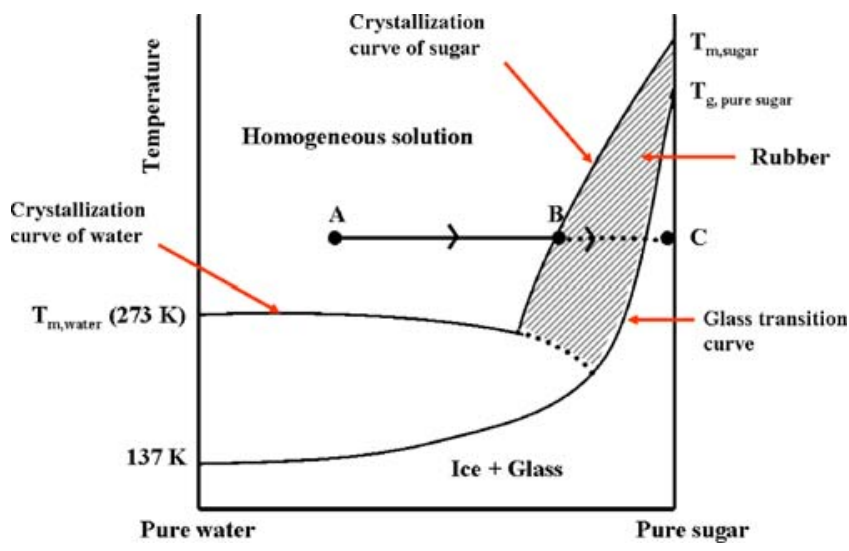

Fig. 8. Vacuum drying and dessication-state-diagram of a binary sugar/water system and the incorporation of a biopharmaceutical in a glassy matrix of sugar at a constant (isothermal) temperature $(\mathrm{A} \rightarrow \mathrm{C})$. $A$, starting composition; $B$, point where the sugar solution passes the crystallization curve of sugar; $C$, dried product in the amorphous glassy state. 
attenuated measles virus for pulmonary vaccination $(109,110)$. SCF drying makes use of a fluid that is supercritical i.e. when both pressure and temperature are above the critical pressure $\left(P_{\mathrm{c}}\right)$ and critical temperature $\left(T_{\mathrm{c}}\right)$, respectively (Fig. 9). Above the critical temperature, it is not possible to convert a gas in the liquid state by increasing the pressure. However, the density of the gas increases continuously with increasing pressure and can be higher than that of a liquid at ambient conditions. The supercritical fluid has gas-like physical properties, such as a high diffusity and low viscosity (111). The application of SCFs by pharmaceutical companies is restricted to supercritical $\mathrm{CO}_{2}\left(\mathrm{SC}-\mathrm{CO}_{2}\right)$, because this $\mathrm{SCF}$ is generally regarded as safe by the FDA, available in large quantities at high purity, inexpensive and has a low $T_{\mathrm{c}}\left(31.5^{\circ} \mathrm{C}\right)$ etc. There are two main principles of SCF drying which may be applicable for drying and formulation of influenza vaccines.

The first concept is spray drying in a supercritical fluid. A vaccine and sugar containing solution is sprayed by atomization into a vessel containing $\mathrm{SC}-\mathrm{CO}_{2}$. Although $\mathrm{SC}-\mathrm{CO}_{2}$ is not completely miscible with water it dissolves in the vaccine sugar solution. However, the vaccine compound and sugar are poorly soluble in $\mathrm{SC}-\mathrm{CO}_{2}$ (antisolvent). As a result the solvent in the vaccine sugar droplets loses solvent power and becomes supersaturated. This in combination with the water transfer from the supersaturated droplets to the $\mathrm{SC}-\mathrm{CO}_{2}$ (extraction) leads to the incorporation of the vaccine compound in a glassy matrix of sugar. Critical in this process is the mass transfer of water to ensure a rapid dehydration in order to prevent crystallization of the stabilizing sugar. The mass transfer can be improved by decreasing the droplet size, decreasing the relative velocity between the droplets and SC$\mathrm{CO}_{2}$ and increasing the $\mathrm{SC}-\mathrm{CO}_{2} /$ vaccine sugar solution ratio (108). Another critical issue in the drying process is the $\mathrm{pH}$ drop (final $\mathrm{pH}$ 2.5-3) due to the dissolution of $\mathrm{CO}_{2}$ in the water phase (108). Since the structure of HA changes below a $\mathrm{pH}$ of approximately 5 , it is essential to use a sufficiently buffered vaccine solution.

In the second concept, the $\mathrm{SC}-\mathrm{CO}_{2}$ is dissolved at high pressure in the solution containing the vaccine compound and sugar and sprayed to atmospheric conditions. Upon spraying, the $\mathrm{CO}_{2}$ expands and droplets break up in smaller droplets, which are then dried by a flow of nitrogen. This process is a

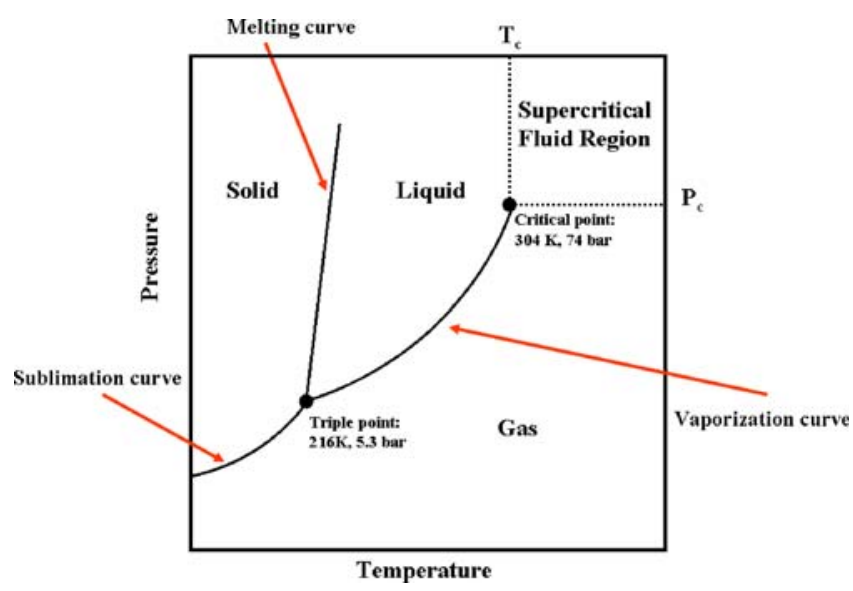

Fig. 9. A pressure-temperature diagram for pure $\mathrm{CO}_{2}$. spray-drying process at relative low-temperature $\left(20-50^{\circ} \mathrm{C}\right.$, but usually somewhat above $\left.T_{\mathrm{c}}\left(32^{\circ} \mathrm{C}\right)(108)\right)$, using the $\mathrm{SC}-\mathrm{CO}_{2}$ as effervescent and extraction agent to enhance the atomization process and water transfer thereby shortening the drying process.

\section{STORAGE STABILITY OF DRIED INFLUENZA VACCINES}

Although the drying process may not affect the structural characteristics of the vaccine, it does not guarantee long-term stability. In the dry state, the long-term stability of the influenza vaccine may still be limited, especially at elevated storage temperatures. The stability of the dried vaccine is mainly dependent on the formulation (composition), the structure in which the vaccine is incorporated in the formulation and, of course, the storage conditions.

It was shown that the storage stability of lyophilized influenza subunit vaccine was dependent on the type of carbohydrate, type of buffer and storage conditions (50). Subunit vaccines lyophilized with trehalose, inulin $0.9 \mathrm{kD}$ or inulin $1.8 \mathrm{kD}$ have been shown to be stable for at least 26 weeks at room temperature. In contrast, vaccine incorporated in a glassy matrix of dextran $56 \mathrm{kD}$ lost its potency during storage for 26 weeks. When influenza subunit vaccine lyophilized with inulin 0.9 or $1.8 \mathrm{kD}$ was stored at $45^{\circ} \mathrm{C}$, the potency of the vaccine was almost completely lost within 4 weeks. In contrast, when trehalose was used as stabilizer the subunit vaccine retained its potency at this temperature for at least 26 weeks. The poor stabilization of HA by dextran might be due to phase separation (during freezing) and/or the bulkiness of dextran (steric hindrance), preventing efficient vitrification and interaction (e.g. hydrogen bonding) with the protein $(58,89,112)$. This is in contrast to the small disaccharide trehalose. The less efficient stabilization of HA at elevated temperatures by the oligosaccharide inulin compared to trehalose might be due to a lower extent and intimacy of interaction (e.g. hydrogen bond formation) (89).

In the same study it was also found that HBS was superior to $\mathrm{PBS}$ in preserving the in vitro immunological properties of $\mathrm{HA}$ in the carbohydrate formulation upon freeze-drying and storage. The antigen activity of the powders decreased more readily when PBS was used instead of HBS. Reasons for this could be an improper inclusion in the glassy matrix due to the $\mathrm{pH}$ shift during freezing with PBS and the capability of HBS to form an amorphous matrix (68) that acts as a stabilizer during freeze-drying and storage.

Maa et al. evaluated the stability of trivalent influenza subunit powder [containing A/Panama (H3N2), A/New Caledonia (H1N1) and B/Yamanashi strains] produced by sprayfreeze drying using highly concentrated feed solutions (35.64 $\mathrm{mg} \mathrm{HA} / \mathrm{ml}$ and $35 \% \mathrm{w} / v$ carbohydrate) (79). Vaccine formulations of different compositions were evaluated for stability:

- A: trehalose/mannitol/dextran $10 \mathrm{kD}=3: 3: 4$ (10\% vaccine)

- B: trehalose $/$ mannitol/arginine glutamate $=4: 2: 4$ (10\% vaccine; $0.5 \%$ polysorbate 80 )

- C: trehalose/mannitol=7:3 (10\% vaccine; $5 \%$ poloxamer 188$)$

During storage for 12 weeks at $40^{\circ} \mathrm{C}$ in sealed glass vials, formulation $\mathrm{A}$ and $\mathrm{B}$ fully retained HA potency whereas 
formulation $\mathrm{C}$ suffered continuous potency loss. This might be due to decrease of the $T_{\mathrm{g}}$ by poloxamer. Although the HA potency was unaffected, formulation B lost its uniform particle properties (shape/flowability) during storage due to crystallization of arginine glutamate. In an additional study formulation A was found to be resistant to humidities of 10 and $40 \%$ relative humidity $(\mathrm{RH})$ for 8 weeks at $40^{\circ} \mathrm{C}$, but gradually lost potency upon storage at $75 \% \mathrm{RH}$.

WIV vaccine powder stabilized with trehalose (trehalose/ virus, 500:1) as produced by Huang et al. showed improved stability compared to liquid WIV vaccine (85). While the liquid formulation lost more than $50 \%$ of its haemagglutination activity upon storage for 2 weeks at $4^{\circ} \mathrm{C} / 25 \% \mathrm{RH}$ and $25^{\circ} \mathrm{C} /$ $25 \% \mathrm{RH}$ the powder formulation retained full haemagglutination activity up to 12 weeks. However, the powder formulation showed an almost instant drop in stability upon storage at $40^{\circ} \mathrm{C} / 75 \% \mathrm{RH}$. This was probably due to crystallization of trehalose resulting from a decrease in $T_{\mathrm{g}}$ to below the storage temperature by the high humidity resulting in an increase in molecular mobility (62).

Inulin sugar glasses have been shown to preserve the structural integrity and biological activity of influenza virosomes during storage (88). Virosomes (225-450 $\mu \mathrm{g} / \mathrm{ml})$ lyophilized with inulin $1.8 \mathrm{kD}(22.5-45 \mathrm{mg} / \mathrm{ml})$ retained HA potency upon storage for 12 weeks at $20^{\circ} \mathrm{C}$. Upon storage at $42^{\circ} \mathrm{C}$ the inulin lyophilized virosomes gradually decreased in HA potency, but to a lower extent than the virosomes lyophilized without sugar. Moreover, virosome aggregation upon storage and subsequent rehydration was visually observed when virosomes were lyophilized without sugar, but this did not occur when lyophilization was done in inulin. The preservation of the vesicular structure in the presence of sugars, in particular inulin is believed to be related to the fact that the oligosaccharide interacts with membrane lipids and as such may preserve the structural and functional features of membrane vesicles during dehydration $(64,113,114)$.

\section{STABILIZATION OF DIFFERENT VACCINE SUBTYPES}

Although only limited research has been done on the storage stability of different influenza vaccines, the extent of stabilization seems to be related to the type of vaccine. Especially the differences in complexity between WIV, virosomes and split or subunit vaccines deserve attention. The most successful stabilization studies have been performed with subunit preparations, which are relatively stable even at elevated temperatures. In contrast, WIV and virosomes incorporated in a glassy sugar matrix appeared to be less stable at comparable conditions.

The main difference between subunit (and split) vaccine compared to WIV and virosomes is the vesicular structure of the latter consisting of lipids, which may explain the less efficient stabilization of the WIV and virosomes. Lipids have a melting point $\left(T_{\mathrm{m}}\right)$ above which they are in the liquid crystalline phase; below this $T_{\mathrm{m}}$ they are in the gel phase. In the hydrated state, for example the $T_{\mathrm{m}}$ for POPC (1Palmitoyl-2-oleoyl-sn-glycero-3-phosphocholine) is about $-1{ }^{\circ} \mathrm{C}$ and rises to about $70^{\circ} \mathrm{C}$ when it is dried without sugars (115). This is due to increase in Van der Waal forces between lipids upon removal of water molecules from the lipid headgroup region. As a result the bilayer undergoes a phase transition during rehydration, which may lead to disturbance of the vesicle (Fig. 10). However, certain carbohydrates can prevent this phase transition, according to the water replacement hypothesis formulated by Crowe et al. (66). Carbohydrates containing many hydroxyl-groups can take over hydrogen bonding to a certain extent, thereby forcing themselves in between the lipid head groups. This results in more space between the lipid molecules and reduction in Van der Waals forces, leading to lower phase transition temperatures. For example, the $T_{\mathrm{m}}$ for POPC in the dry state in the presence of trehalose is lowered to $-20^{\circ} \mathrm{C}(115)$. In addition carbohydrates that vitrify in between the bilayers tend to keep the membrane in the phase it was at the moment of vitrification (116-118) and prevent aggregation/ fusion due to particle isolation (75).

Improved stability of vesicular lipid bilayer systems (like liposomes, red blood cells, or other mammalian cells) was found when a stabilizer (like trehalose or inulin) was present at both sides of the lipid bilayer $(66,113-115,117,119)$. Lack of a stabilizer in the vesicle interior can result in (partial) reorganization of the lipids and subsequent phase transitions. In the studies performed on stabilization of virosomes and WIV, the inside of these vaccine particles lacked the presence of carbohydrate, providing the opportunity of (partial) reorganization of the lipids and subsequent phase transitions. As a result WIV and virosomes incorporated in sugar glasses might have a reduced shelf-life compared to subunit and split vaccines incorporated in sugar glass. Stabilization of lyophilized virosomes may be improved by preparation of virosomes in the presence of sugar (which results in sugar inside the virosome) before formulation and lyophilization. Moreover, also stabilization of WIV vaccines may be improved by loading WIVparticles with sugar from an "extracellular" medium through a combination of osmotic imbalance and phospholipid phase transitions as has been shown to be successful for stabilization of red blood cells (119). In addition, sugar uptake by WIVparticles may be facilitated by increasing the membrane fluidity with compounds such as benzyl alcohol or other weak surfactants (119). In conclusion, stabilization of each type of vaccine should be optimized individually.

\section{Lyophilization}

\section{Rehydration (room temperature)}

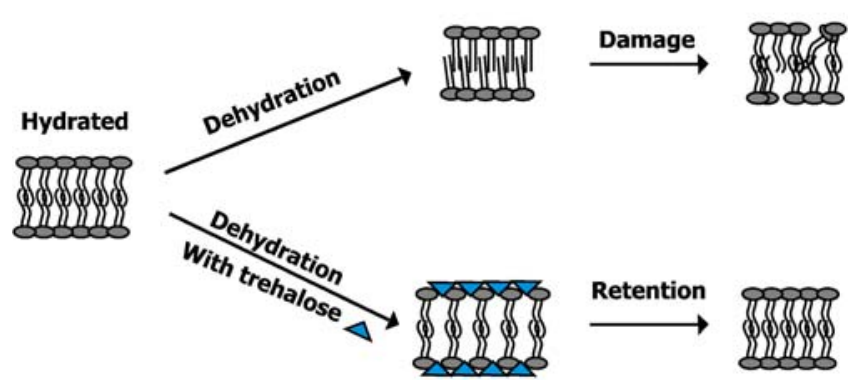

Fig. 10. Water replacement hypothesis for lipid bilayers. The diagram shows how trehalose is thought to stabilize dry lipid bilayers (adopted from Crowe et al. (66)). 


\section{ANALYTICAL ISSUES}

\section{Determinants and Methods to Examine Vaccine Stability/Integrity}

The requirements for characterizing proteins/peptides and vaccines are different. For the former, comprehensive characterizations such as purity and degradation products are required. For vaccines these are less stringent and normally focuses on potency and immunigenicity. One of the methods that often has been used to reveal integrity of the antigenic structure of HA in vaccine formulations after the formulation processes and/or storage is the single radial immunodiffusion (SRID) assay. For several decades, this standardized method has been used to determine the antigen content (HA potency) of all human inactivated influenza vaccines, as recommended by the European Pharmacopoeia and the WHO $(44,120)$. SRID is based on the diffusion of viral antigen in an agarose gel containing specific antibodies to the antigen measured.

However, for the determination of antigen integrity a SRID assay may not be sufficient. The SRID assay is based on the binding of antibodies to HA and does not address the antigen's stability. In case no structural alterations in HA are detected by SRID this does not guarantee a complete absence of conformational changes, since the method may not reveal every structural change.

Although the value of treating vaccine formulations using comparable standards as the pharmaceutical protein products is not clear at this time, combining SRID analyses with additional analytical techniques, like fluorescence spectroscopy, circular dichroism spectroscopy, surface plasmon resonance transfer (SPR), asymmetric flow Field Flow Fractionation (AFFF), reversed-phase high performance liquid chromatography (RP-HPLC), electron microscopy and the use of proteolytic assays may give more complete information on the structural state of $\mathrm{HA}$ in the product. However, even with the combination of all techniques it is impossible to detect every possible structural change in large and complex proteins like HA.

\section{Vaccine Integrity vs. Immunogenicity}

Until today only limited information is available on the effects of structural changes of the vaccine compounds on the final immune response in humans. The effects of low $\mathrm{pH}$, detergents or process stresses on the immunogenicity of the vaccine may not be simply represented by changes in HA potency determined in vitro. For this purpose well designed studies using appropriate animal models or even human volunteers should be conducted. In addition the critical endpoints that are to be defined should be based on the desired or expected type of immune response in relation to the presentational form of HA, e.g. subunit, virosomal and WIV. In a study of Babiuk et al. it was shown that changes in the production process of influenza split vaccine can have remarkable effects on the immunogenicity of the vaccine (121), while no changes in HA potency may be revealed by SRID. Due to a new viral splitting procedure the amount of un-split virions and aggregates, in the split vaccine were increased. This led to a change in the immune response to a greater Th2 cytokine pattern with potential implications for vaccine safety and efficacy. This shows that solely determining the HA content will not suffice as determinant for the immunogenicity of the vaccine.

In addition, criteria should be formulated to address the relevant physical and functional properties for each vaccine type. For example WIV and virosomal vaccines may have immunological advantages over subunit vaccine related to their particulate form and/or ability to deliver material to the cytoplasm of APCs. Therefore, appropriate criteria should be formulated for these functional characteristics like fusion activity. Strikingly, there is no criterion for vesicular size mentioned in the European Pharmacopoeia for WIV vaccines, while on the other hand the size of virosomes should be between 100 and $500 \mathrm{~nm}$ (120).

\section{APPLICATION OF DRY INFLUENZA VACCINE FORMULATIONS}

Dried influenza vaccines, having an improved stability, can be used for reconstitution and subsequent for conventional parenteral administration. However, having the vaccine in the dry state offers the opportunity to deliver the vaccine via non-parenteral dosage forms. In the past decades researchers have used dry influenza vaccine formulations for the development of epidermal, oral, nasal or pulmonary vaccines (Table II). However, the development of dry-state influenza vaccine forms is still in a very early stage and for a launch of an approved product, data on pre-clinical and human clinical studies are needed besides data on (long-term) stability.

The delivery methods using dry influenza vaccine formulations that are tested in phase I clinical trials are epidermal powder delivery and oral delivery $(80,84,122,123)$. During epidermal powder delivery, vaccine powder particles with a high particle density and a particle size of $20-70 \mu \mathrm{m}$ are accelerated to a high speed with a powder jet injector (PowderJect, PowderJect Pharmaceuticals) such that the particles penetrate the stratum corneum and land in the epidermis. Powders for epidermal immunization have been made by both desiccation/grinding/sieving and spray-freeze drying $(78,79,82,83)$. Important factors for the design of these powders were a high particle density and a particle size of 20-70 $\mu \mathrm{m}$ for effective penetration to the epidermis (124). In pre-clinical studies it was shown that immunization of mice with influenza vaccine powder using the powder jet injector results in antibody responses and protective immunity against homologous and heterologous influenza viruses $(78,82,125,126)$. In the phase I clinical trial it was found that epidermal powder immunization of human with influenza vaccine powder using a PowderJect ND5.2 is safe and induces humoral immune responses (126). In this trial it was also found that compared to the conventional i.m. vaccination seroconversion and geometric mean titers were equivalent or higher after epidermal immunization with influenza vaccine powder. Although this study showed promising results additional studies with higher numbers of subjects are needed to prove the safety and efficacy of epidermal powder immunization.

Oral immunization of humans with influenza vaccine powder has been studied in the 1980s. In clinical studies by 
Lazzell et al. (80), Bergmann et al. (123) and later by Moldoveanu et al. (84) it was shown that ingestion of inactivated influenza virus vaccine powders in enteric-coated capsules stimulates local synthesis of secretory $\operatorname{IgA}(\operatorname{sg} \mathrm{A})$ antibody in human nasal secretions. However, no systemic immune responses were elicited from ingestion of the vaccines, responses that are needed to fulfill regulatory criteria for vaccine immunogenicity (127).

Nasal delivery of liquid LAIV vaccine is the only nonparenteral immunization method that is commercialized so far. Nasal delivery of influenza vaccine powders is attractive since devices have been developed for intranasal delivery (128), and intranasally delivery of droplets larger than $50 \mu \mathrm{m}$ is highly reproducible $(129,130)$. One pre-clinical study on nasal delivery of vaccine powders has been reported (85). In the study of Huang et al. it was shown that nasal delivered whole inactivated influenza vaccine powder co-formulated with a mucoadhesive compound elicited significant serum antibody and nasal IgA responses in rats. Clinical studies should be performed to show the efficacy of this vaccine powder in human.

Pulmonary delivery has been described as a promising strategy for vaccination $(128,131,132)$ and has recently been evaluated in pre-clinical studies. In a study by Smith et al. it was shown that pulmonary delivery of a spray-dried lipid formulation containing split influenza vaccine in rats resulted in substantial systemic immune responses, but no mucosal IgA in the respiratory tract (9). Also a SFD vaccine powder has been evaluated for pulmonary vaccination. In the preclinical study, pulmonary vaccination of mice with vaccine powder resulted in the induction of mucosal, systemic humoral and cell-mediated immune responses, which were even higher than after i.m. immunization of mice with conventional liquid vaccine (77). These pre-clinical studies demonstrate the promising potential of dry powder inhalation for influenza vaccination. However, until today the safety and efficacy of influenza vaccination using appropriate dry powder inhalers (DPI's) is not proven in clinical trials.

\section{CONCLUSIONS}

From the investigations performed so far, it can be concluded, that incorporation of influenza vaccines in amorphous glassy carbohydrate matrices has the potential to solve the problems associated with the cold-chain requirement of liquid vaccines. However, many aspects of the stabilization of influenza vaccines, in particular the comparison between the different drying methods for the production of stabilized influenza vaccines, have to be further investigated. It is clear that not all drying methods are suitable. In addition, each vaccine type may possess its own intrinsic sensitivity to different process stresses and have its own limitations, e.g., due to their particulate nature, virosomes and WIV appear to possess a higher sensitivity to shear stresses during atomization applied by spray (freeze) drying than subunit and split vaccines. As a result the incorporation of a vaccine compound in carbohydrate glasses should be optimized by both formulation and drying process considerations. Moreover, not only vaccine-typedependent formulation and process design, but also the analytical challenges as well as methods to establish the critical parameters for vaccine stability, have to be addressed to guarantee a stable and effective solid influenza vaccine. Since the development of dry-state influenza vaccine is still in a very early stage, additional data on long-term stability of dry influenza vaccine formulations and pre- and clinical studies are needed before an approved product can be launched on the market.

Open Access This article is distributed under the terms of the Creative Commons Attribution Noncommercial License which permits any noncommercial use, distribution, and reproduction in any medium, provided the original author(s) and source are credited.

\section{REFERENCES}

1. WHO. WHO Media Influenza Factsheet No. 211. (2003).

2. Y. Suzuki. Sialobiology of influenza: Molecular mechanism of host range variation of influenza viruses. Biol. Pharm. Bull. 28:399-408 (2005).

3. I. Stephenson, K. G. Nicholson, J. M. Wood, M. C. Zambon, and J. M. Katz. Confronting the avian influenza threat: Vaccine development for a potential pandemic. Lancet Infect. Dis. 4:499-509 (2004).

4. R. J. Cox, K. A. Brokstad, and P. Ogra. Influenza virus: Immunity and vaccination strategies. Comparison of the immune response to inactivated and live, attenuated influenza vaccines. Scand. J. Immunol. 59:1-15 (2004).

5. The European Agency for the Evaluation of Medicinal Products (EMEA) Committee for Proprietary Medicinal Products (CPMP). Guideline on Dossier Structure and Content for Pandemic Influenza Vaccine Marketing Authorisation Application. CPMP/VEG/4717/03 (2004).

6. E. L. Giudice, and J. D. Campbell. Needle-free vaccine delivery. Adv. Drug Deliv. Rev. 58:68-89 (2006).

7. L. C. Freytag, and J. D. Clements. Mucosal adjuvants. Vaccine 23:1804-1813 (2005).

8. J. Holmgren, and C. Czerkinsky. Mucosal immunity and vaccines. Nat. Med. 11:S45-S53 (2005).

9. D. J. Smith, S. Bot, L. Dellamary, and A. Bot. Evaluation of novel aerosol formulations designed for mucosal vaccination against influenza virus. Vaccine 21:2805-2812 (2003).

10. J. Wilschut, J. E. McElhaney, and A. M. Palache. Rapid Reference Influenza. Mosby/Elsevier Science, London, 2006.

11. I. A. Wilson, and N. J. Cox. Structural basis of immune recognition of influenza virus hemagglutinin. Annu. Rev. Immunol. 8:737-771 (1990).

12. D. C. Wiley, I. A. Wilson, and J. J. Skehel. Structural identification of the antibody-binding sites of Hong Kong influenza haemagglutinin and their involvement in antigenic variation. Nature 289:373-378 (1981).

13. Y. Amano, and Q. Cheng. Detection of influenza virus: traditional approaches and development of biosensors. Anal. Bioanal. Chem. 381:156-164 (2005).

14. B. L. Ligon. Avian influenza virus H5N1: A review of its history and information regarding its potential to cause the next pandemic. Semin. Pediatr. Infect. Dis. 16:326-335 (2005).

15. A. S. Fauci. Pandemic influenza threat and preparedness. Emerg. Infect. Dis. 12:73-77 (2006).

16. S. S. Wong, and K. Y. Yuen. Avian influenza virus infections in humans. Chest 129:156-168 (2006).

17. C. J. Luke, and K. Subbarao. Vaccines for pandemic influenza. Emerg. Infect. Dis. 12:66-72 (2006).

18. R. Belshe, M. S. Lee, R. E. Walker, J. Stoddard, and P. M. Mendelman. Safety, immunogenicity and efficacy of intranasal, live attenuated influenza vaccine. Expert Rev. Vaccines 3:643654 (2004).

19. J. S. Abramson. Intranasal, cold-adapted, live, attenuated influenza vaccine. Pediatr. Infect. Dis. J. 18:1103-1104 (1999).

20. L. G. Rudenko, N. H. Arden, E. Grigorieva, A. Naychin, A. Rekstin, A. I. Klimov, S. Donina, J. Desheva, R. C. Holman, A. DeGuzman, N. J. Cox, and J. M. Katz. Immunogenicity and efficacy of Russian live attenuated and US inactivated influenza 
vaccines used alone and in combination in nursing home residents. Vaccine 19:308-318 (2000).

21. A. Huckriede, L. Bungener, T. Stegmann, T. Daemen, J. Medema, A. M. Palache, and J. Wilschut. The virosome concept for influenza vaccines. Vaccine. 23(Suppl 1):S26-S38 (2005).

22. R. Brands, J. Visser, J. Medema, A. M. Palache, and G. J. van Scharrenburg. Influvac: A safe Madin Darby Canine Kidney (MDCK) cell culture-based influenza vaccine. Dev. Biol. Stand. 98:93-100 (1999) discussion 111.

23. O. Kistner, P. N. Barrett, W. Mundt, M. Reiter, S. SchoberBendixen, and F. Dorner. Development of a mammalian cell (Vero) derived candidate influenza virus vaccine. Vaccine 16:960-968 (1998).

24. A. M. Palache, H. S. Scheepers, V. de Regt, P. van Ewijk, M. Baljet, R. Brands, and G. J. van Scharrenburg. Safety, reactogenicity and immunogenicity of Madin Darby Canine Kidney cell-derived inactivated influenza subunit vaccine. A meta-analysis of clinical studies. Dev. Biol. Stand. 98:115-125 (1999) discussion 133-134.

25. M. G. Pau, C. Ophorst, M. H. Koldijk, G. Schouten, M. Mehtali, and F. Uytdehaag. The human cell line PER.C6 provides a new manufacturing system for the production of influenza vaccines. Vaccine 19:2716-2721 (2001).

26. E. I. Budowsky, A. Smirnov Yu, and S. F. Shenderovich. Principles of selective inactivation of viral genome. VIII. The influence of beta-propiolactone on immunogenic and protective activities of influenza virus. Vaccine 11:343-348 (1993).

27. D. W. Barry, R. E. Mayner, E. Staton, R. C. Dunlap, S. C. Rastogi, J. E. Hannah, R. J. Blackburn, D. F. Nortman, and P. R. Graze. Comparative trial of influenza vaccines. I. Immunogenicity of whole virus and split product vaccines in man. Am. J. Epidemiol. 104:34-46 (1976).

28. P. A. Gross, F. A. Ennis, P. F. Gaerlan, L. J. Denson, C. R. Denning, and D. Schiffman. A controlled double-blind comparison of reactogenicity, immunogenicity, and protective efficacy of whole-virus and split-product influenza vaccines in children. J. Infect. Dis. 136:623-632 (1977).

29. R. J. Cox, A. O. Hovden, K. A. Brokstad, E. Szyszko, A. S. Madhun, and L. R. Haaheim. The humoral immune response and protective efficacy of vaccination with inactivated split and whole influenza virus vaccines in $\mathrm{BALB} / \mathrm{c}$ mice. Vaccine 24:6585-6587 (2006).

30. R. Jennings, R. M. Pemberton, T. L. Smith, T. Amin, and C. W. Potter. Demonstration of an immunosuppressive action of detergent-disrupted influenza virus on the antibody response to inactivated whole virus vaccine. J. Gen. Virol. 68(Pt 2):441-450 (1987).

31. C. S. Reiss, and J. L. Schulman. Cellular immune responses of mice to influenza virus vaccines. J. Immunol. 125:2182-2188 (1980).

32. X. Lu, L. E. Edwards, J. A. Desheva, D. C. Nguyen, A. Rekstin, I. Stephenson, K. Szretter, N. J. Cox, L. G. Rudenko, A. Klimov, and J. M. Katz. Cross-protective immunity in mice induced by live-attenuated or inactivated vaccines against highly pathogenic influenza A (H5N1) viruses. Vaccine. 24:6588-6593 (2006).

33. F. A. Ennis, A. H. Rook, Y. H. Qi, G. C. Schild, D. Riley, R. Pratt, and C. W. Potter. HLA restricted virus-specific cytotoxic T-lymphocyte responses to live and inactivated influenza vaccines. Lancet. 2:887-891 (1981).

34. U. Kees, and P. H. Krammer. Most influenza A virus-specific memory cytotoxic $\mathrm{T}$ lymphocytes react with antigenic epitopes associated with internal virus determinants. J. Exp. Med. 159:365-377 (1984)

35. I. Stephenson, and K. G. Nicholson. Influenza: Vaccination and treatment. Eur. Respir. J. 17:1282-12893 (2001).

36. W. A. Keitel, and R. L. Atmar. Preparing for a possible pandemic: Influenza A/H5N1 vaccine development. Curr. Opin. Pharmacol. 7:484-490 (2007).

37. T. Stegmann, H. W. Morselt, F. P. Booy, J. F. van Breemen, G. Scherphof, and J. Wilschut. Functional reconstitution of influenza virus envelopes. Embo J. 6:2651-2659 (1987).

38. R. Bron, A. Ortiz, J. Dijkstra, T. Stegmann, and J. Wilschut. Preparation, properties, and applications of reconstituted influenza virus envelopes (virosomes). Methods Enzymol. 220:313-331 (1993).
39. J. de Jonge, P. Schoen, W. ter Veer, T. Stegmann, J. Wilschut, and A. Huckriede. Use of a dialyzable short-chain phospholipid for efficient solubilization and reconstitution of influenza virus envelopes. Biochim. Biophys. Acta. 1758:527-536 (2006).

40. I. A. de Bruijn, J. Nauta, W. C. Cramer, L. Gerez, and A. M. Palache. Clinical experience with inactivated, virosomal influenza vaccine. Vaccine 23(Suppl 1):S39-S49 (2005).

41. I. de Bruijn, I. Meyer, L. Gerez, J. Nauta, K. Giezeman, and B. Palache. Antibody induction by virosomal, MF59-adjuvanted, or conventional influenza vaccines in the elderly. Vaccine 26:119-127 (2007).

42. W. E. Beyer, A. M. Palache, J. C. de Jong, and A. D Osterhaus. Cold-adapted live influenza vaccine versus inactivated vaccine: Systemic vaccine reactions, local and systemic antibody response, and vaccine efficacy. A meta-analysis. Vaccine 20:1340-1353 (2002).

43. M. L. Clements, R. F. Betts, E. L. Tierney, and B. R. Murphy. Serum and nasal wash antibodies associated with resistance to experimental challenge with influenza A wild-type virus. J. Clin. Microbiol. 24:157-160 (1986).

44. WHO Department of Immunization, Vaccines and Biologicals. Temperature sensitivity of vaccines. (2006).

45. ICH, Q1A (R2). Stability testing guidelines: Stability testing of new drug substances and products. ICH step 5. CPMP/ICH/2736/99.

46. ICH, Q5C. Stability testing of biotechnological/biological products. ICH step 4. CPMP/ICH/138/95.

47. F. Coenen, J. T. Tolboom, and H. W. Frijlink. Stability of influenza sub-unit vaccine. Does a couple of days outside the refrigerator matter? Vaccine 24:525-531 (2006).

48. S. L. Block, K. S. Reisinger, M. Hultquist, and R. E. Walker. Comparative immunogenicities of frozen and refrigerated formulations of live attenuated influenza vaccine in healthy subjects. Antimicrob. Agents Chemother. 51:4001-4008 (2007).

49. D. M. Luykx, M. G. Casteleijn, W. Jiskoot, J. Westdijk, and P. M. Jongen. Physicochemical studies on the stability of influenza haemagglutinin in vaccine bulk material. Eur. J. Pharm. Sci. 23:65-75 (2004).

50. J. P. Amorij, J. Meulenaar, W. L. Hinrichs, T. Stegmann, A. Huckriede, F. Coenen, and H. W. Frijlink. Rational design of an influenza subunit vaccine powder with sugar glass technology: Preventing conformational changes of haemagglutinin during freezing and freeze-drying. Vaccine 25:6447-6457 (2007).

51. S. E. Zweig. Advances in vaccine stability monitoring technology. Vaccine 24:5977-5985 (2006).

52. J. S. Oxford, C. Manuguerra, O. Kistner, A. Linde, M. Kunze, W. Lange, B. Schweiger, G. Spala, H. Rebelo de Andrade, P. R. Perez Brena, J. Beytout, L. Brydak, D. Caraffa de Stefano, O. Hungnes, J. Kyncl, E. Montomoli, A. Gil de Miguel, R. Vranckx, and A. Osterhaus. A new European perspective of influenza pandemic planning with a particular focus on the role of mammalian cell culture vaccines. Vaccine 23:5440-5449 (2005).

53. A. D. Osterhaus. Pre- or post-pandemic influenza vaccine? Vaccine 25:4983-4984 (2007).

54. P. E. Fine. Poliomyelitis: Very small risks and very large risks. Lancet Neurol. 3:703 (2004).

55. S. Mitragotri. Immunization without needles. Nat. Rev. Immunol. 5:905-916 (2005).

56. F. Y. Liew, S. M. Russell, G. Appleyard, C. M. Brand, and J. Beale. Cross-protection in mice infected with influenza A virus by the respiratory route is correlated with local $\operatorname{IgA}$ antibody rather than serum antibody or cytotoxic T cell reactivity. Eur. J. Immunol. 14:350-356 (1984).

57. T. M. Tumpey, M. Renshaw, J. D. Clements, and J. M. Katz. Mucosal delivery of inactivated influenza vaccine induces Bcell-dependent heterosubtypic cross-protection against lethal influenza A H5N1 virus infection. J. Virol. 75:5141-5150 (2001).

58. T. W. Randolph. Phase separation of excipients during lyophilization: Effects on protein stability. J. Pharm. Sci. 86:11981203 (1997).

59. C. Schebor, L. Burin, M. P. Buera, J. M. Aguilera, and J. Chirife. Glassy state and thermal inactivation of invertase and lactase in dried amorphous matrices. Biotechnol. Prog. 13:857-863 (1997).

60. L. Slade, and H. Levine. Non-equilibrium behavior of small carbohydrate-water systems. Pure Appl. Chem. 60:1841-1864 (1988). 
61. L. Slade, and H. Levine. Water and the glass transition: dependance of the glass transition on the composition and chemical structure: Special implications for flour functionality in cooky baking. J. Food Eng. 24:431-509 (1995).

62. W. L. Hinrichs, M. G. Prinsen, and H. W. Frijlink. Inulin glasses for the stabilization of therapeutic proteins. Int. J. Pharm. 215:163-174 (2001).

63. H. J. Eriksson, W. L. Hinrichs, B. van Veen, G. W. Somsen, G. J. de Jong, and H. W. Frijlink. Investigations into the stabilisation of drugs by sugar glasses: I. Tablets prepared from stabilised alkaline phosphatase. Int. J. Pharm. 249:59-70 (2002).

64. D. K. Hincha, E. Zuther, E. M. Hellwege, and A. G. Heyer. Specific effects of fructo- and gluco-oligosaccharides in the preservation of liposomes during drying. Glycobiology. 12:103110 (2002).

65. W. Q. Sun, A. C. Leopold, L. M. Crowe, and J. H. Crowe. Stability of dry liposomes in sugar glasses. Biophys. J. 70:17691776 (1996).

66. L. M. Crowe, J. H. Crowe, A. Rudolph, C. Womersley, and L. Appel. Preservation of freeze-dried liposomes by trehalose. Arch. Biochem. Biophys. 242:240-247 (1985).

67. J. H. Crowe, L. M. Crowe, J. F. Carpenter, and C. Aurell Wistrom. Stabilization of dry phospholipid bilayers and proteins by sugars. Biochem. J. 242:1-10 (1987).

68. W. L. Hinrichs, N. N. Sanders, S. C. De Smedt, J. Demeester, and H. W. Frijlink. Inulin is a promising cryo- and lyoprotectant for PEGylated lipoplexes. J. Control. Release. 103:465-479 (2005).

69. W. L. Hinrichs, F. A. Mancenido, N. N. Sanders, K. Braeckmans, S. C. De Smedt, J. Demeester, and H. W. Frijlink. The choice of a suitable oligosaccharide to prevent aggregation of PEGylated nanoparticles during freeze thawing and freeze drying. Int. $J$. Pharm. 311:237-244 (2006).

70. D. A. Yannarell, K. M. Goldberg, and R. N. Hjorth. Stabilizing cold-adapted influenza virus vaccine under various storage conditions. J. Virol. Methods. 102:15-25 (2002)

71. J. A. Levy, and A. H. Fieldsteel. Freeze-drying is an effective method for preserving infectious type $\mathrm{C}$ retroviruses. J. Virol. Methods. 5:165-171 (1982).

72. R. M. Bieganski, A. Fowler, J. R. Morgan, and M. Toner. Stabilization of active recombinant retroviruses in an amorphous dry state with trehalose. Biotechnol. Prog. 14:615-620 (1998).

73. M. A. Croyle, B. J. Roessler, B. L. Davidson, J. M. Hilfinger, and G. L. Amidon. Factors that influence stability of recombinant adenoviral preparations for human gene therapy. Pharm. Dev. Technol. 3:373-383 (1998).

74. S. D. Allison, M. C. Molina, and T. J. Anchordoquy. Stabilization of lipid/DNA complexes during the freezing step of the lyophilization process: The particle isolation hypothesis. Biochim. Biophys. Acta. 1468:127-138 (2000).

75. M. C. Molina, T. K. Armstrong, Y. Zhang, M. M. Patel, Y. K. Lentz, and T. J. Anchordoquy. The stability of lyophilized lipid/ DNA complexes during prolonged storage. J. Pharm. Sci. 93:2259-2273 (2004).

76. J. F. Carpenter, and J. H. Crowe. An infrared spectroscopic study of the interactions of carbohydrates with dried proteins. Biochemistry. 28:3916-3922 (1989).

77. J. P. Amorij, V. Saluja, A. H. Petersen, W. L. Hinrichs, A. Huckriede, and H. W. Frijlink. Pulmonary delivery of an inulinstabilized influenza subunit vaccine prepared by spray-freeze drying induces systemic, mucosal humoral as well as cellmediated immune responses in $\mathrm{BALB} / \mathrm{c}$ mice. Vaccine 25:8707-8717 (2007).

78. D. Chen, R. Endres, Y. F. Maa, C. R. Kensil, P. WhitakerDowling, A. Trichel, J. S. Youngner, and L. G. Payne. Epidermal powder immunization of mice and monkeys with an influenza vaccine. Vaccine 21:2830-2836 (2003).

79. Y. F. Maa, M. Ameri, C. Shu, L. G. Payne, and D. Chen. Influenza vaccine powder formulation development: Sprayfreeze-drying and stability evaluation. J. Pharm. Sci. 93:19121923 (2004).

80. V. Lazzell, R. H. Waldman, C. Rose, R. Khakoo, A. Jacknowitz, and S. Howard. Immunization against influenza in humans using an oral enteric-coated killed virus vaccine. J. Biol. Stand. 12:315-321 (1984).
81. M. Singh, M. Briones, and D. T. O'Hagan. A novel bioadhesive intranasal delivery system for inactivated influenza vaccines. J. Control. Release. 70:267-276 (2001).

82. D. Chen, R. L. Endres, C. A. Erickson, K. F. Weis, M. W. McGregor, Y. Kawaoka, and L. G. Payne. Epidermal immunization by a needle-free powder delivery technology: Immunogenicity of influenza vaccine and protection in mice. Nat. Med. 6:1187-1190 (2000).

83. D. Chen, R. L. Endres, C. A. Erickson, Y. F. Maa, and L. G. Payne. Epidermal powder immunization using non-toxic bacterial enterotoxin adjuvants with influenza vaccine augments protective immunity. Vaccine 20:2671-2679 (2002).

84. Z. Moldoveanu, M. L. Clements, S. J. Prince, B. R. Murphy, and J. Mestecky. Human immune responses to influenza virus vaccines administered by systemic or mucosal routes. Vaccine 13:1006-1012 (1995).

85. J. Huang, R. J. Garmise, T. M. Crowder, K. Mar, C. R. Hwang, A. J. Hickey, J. A. Mikszta, and V. J. Sullivan. A novel dry powder influenza vaccine and intranasal delivery technology: induction of systemic and mucosal immune responses in rats. Vaccine 23:794-801 (2004).

86. R. J. Garmise, K. Mar, T. M. Crowder, C. R. Hwang, M. Ferriter, J. Huang, J. A. Mikszta, V. J. Sullivan, and A. J. Hickey. Formulation of a dry powder influenza vaccine for nasal delivery. AAPS PharmSciTech. 7:E19 (2006).

87. A. I. Bot, D. J. Smith, S. Bot, L. Dellamary, T. E. Tarara, S. Harders, W. Phillips, J. G. Weers, and C. M. Woods. Receptormediated targeting of spray-dried lipid particles coformulated with immunoglobulin and loaded with a prototype vaccine. Pharm. Res. 18:971-979 (2001).

88. J. de Jonge, J. P. Amorij, W. L. Hinrichs, J. Wilschut, A. Huckriede, and $\mathrm{H}$. W. Frijlink. Inulin sugar glasses preserve the structural integrity and biological activity of influenza virosomes during freeze-drying and storage. Eur. J. Pharm. Sci. 32:33-44 (2007).

89. W. Wang. Lyophilization and development of solid protein pharmaceuticals. Int. J. Pharm. 203:1-60 (2000).

90. A. M. Abdul-Fattah, V. Truong-Le, L. Yee, E. Pan, Y. Ao, D. S. Kalonia, and M. J. Pikal. Drying-induced variations in physicochemical properties of amorphous pharmaceuticals and their impact on Stability II: Stability of a vaccine. Pharm. Res. 24:715-727 (2007)

91. T. Korte, K. Ludwig, Q. Huang, P. S. Rachakonda, and A. Herrmann. Conformational change of influenza virus hemagglutinin is sensitive to ionic concentration. Eur. Biophys. J. 36:327-335 (2007).

92. J. H. Eriksson, W. L. Hinrichs, G. J. de Jong, G. W. Somsen, and $\mathrm{H}$. W. Frijlink. Investigations into the stabilization of drugs by sugar glasses: III. The influence of various high-pH buffers. Pharm. Res. 20:1437-1443 (2003).

93. S. A. Shoyele, and S. Cawthorne. Particle engineering techniques for inhaled biopharmaceuticals. Adv. Drug. Deliv. Rev. 58:1009-1029 (2006).

94. J. Wilschut, J. de Jonge, A. Huckriede, J. P. Amorij, W. L. Hinrichs, and H. W. Frijlink. Preservation of influenza virosome structure and function during freeze-drying and storage. J. Liposome Res. 17:173-182 (2007).

95. A. Millqvist-Fureby, M. Malmsten, and B. Bergenstahl. Spraydrying of trypsin-surface characterisation and activity preservation. Int. J. Pharm. 188:243-253 (1999).

96. M. Adler, M. Unger, and G. Lee. Surface composition of spraydried particles of bovine serum albumin/trehalose/surfactant. Pharm. Res. 17:863-870 (2000).

97. H. R. Costantino, J. D. Andya, P. A. Nguyen, N. Dasovich, T. D. Sweeney, S. J. Shire, C. C. Hsu, and Y. F. Maa. Effect of mannitol crystallization on the stability and aerosol performance of a spray-dried pharmaceutical protein, recombinant humanized anti-IgE monoclonal antibody. J. Pharm. Sci. 87:1406-1411 (1998)

98. R. Surana, A. Pyne, and R. Suryanarayanan. Effect of preparation method on physical properties of amorphous trehalose. Pharm. Res. 21:1167-1176 (2004).

99. R. T. Forbes, K. G. Davis, M. Hindle, J. G. Clarke, and J. Maas. Water vapor sorption studies on the physical stability of a series of spray-dried protein/sugar powders for inhalation. J. Pharm. Sci. 87:1316-1321 (1998). 
100. J. Elversson, and A. Millqvist-Fureby. Particle size and density in spray drying-effects of carbohydrate properties. J. Pharm. Sci. 94:2049-2060 (2005)

101. Y. H. Liao, M. B. Brown, T. Nazir, A. Quader, and G. P. Martin. Effects of sucrose and trehalose on the preservation of the native structure of spray-dried lysozyme. Pharm. Res. 19:18471853 (2002).

102. C. Bosquillon, P. G. Rouxhet, F. Ahimou, D. Simon, C. Culot, V. Preat, and R. Vanbever. Aerosolization properties, surface composition and physical state of spray-dried protein powders. J. Control. Release. 99:357-367 (2004).

103. S. Branchu, R. T. Forbes, P. York, S. Petren, H. Nyqvist, and O. Camber. Hydroxypropyl-beta-cyclodextrin inhibits spray-drying-induced inactivation of beta-galactosidase. J. Pharm. Sci. 88:905-911 (1999).

104. P. D. Orford, R. Parker, and S. G. Ring. Aspects of the glass transition behaviour of mixtures of carbohydrates of low molecular weight. Carbohydr. Res. 196:11-18 (1990).

105. A. Saleki-Gerhardt, and G. Zografi. Non-isothermal and isothermal crystallization of sucrose from the amorphous state. Pharm. Res. 11:1166-1173 (1994).

106. A. Aksan, and M. Toner. Isothermal desiccation and vitrification kinetics of trehalose-dextran solutions. Langmuir. 20:55215529 (2004)

107. U. B. Kompella, and K. Koushik. Preparation of drug delivery systems using supercritical fluid technology. Crit. Rev. Ther. Drug Carrier Syst. 18:173-199 (2001).

108. N. Jovanovic, A. Bouchard, G. W. Hofland, G. J. Witkamp, D. J. Crommelin, and W. Jiskoot. Stabilization of proteins in dry powder formulations using supercritical fluid technology. Pharm. Res. 21:1955-1969 (2004).

109. M. Amidi, H. C. Pellikaan, H. Hirschberg, A. H. de Boer, D. J. Crommelin, W. E. Hennink, G. Kersten, and W. Jiskoot. Diphtheria toxoid-containing microparticulate powder formulations for pulmonary vaccination: preparation, characterization and evaluation in guinea pigs. Vaccine 25:6818-6829 (2007).

110. J. L. Burger, S. P. Cape, C. S. Braun, D. H. McAdams, J. A. Best, P. Bhagwat, P. Pathak, L. G. Rebits, and R. E. Sievers. Stabilizing formulations for inhalable powders of live-attenuated measles virus vaccine. J. Aerosol. Med. 21:1-10 (2008).

111. E. Reverchon. Supercritical antisolvent precipitation of microand nano-particles. J. Supercrit. Fluids 15:1-21 (1999).

112. S. D. Allison, B. Chang, T. W. Randolph, and J. F. Carpenter. Hydrogen bonding between sugar and protein is responsible for inhibition of dehydration-induced protein unfolding. Arch. Biochem. Biophys. 365:289-298 (1999).

113. I. J. Vereyken, V. Chupin, F. A. Hoekstra, S. C. Smeekens, and B. de Kruijff. The effect of fructan on membrane lipid organization and dynamics in the dry state. Biophys. $J$. 84:3759-3766 (2003).

114. I. J. Vereyken, V. Chupin, A. Islamov, A. Kuklin, D. K. Hincha, and B. de Kruijff. The effect of fructan on the phospholipid organization in the dry state. Biophys. J. 85:3058-3065 (2003).

115. J. H. Crowe, L. M. Crowe, A. E. Oliver, N. Tsvetkova, W. Wolkers, and F. Tablin. The trehalose myth revisited: Introduction to a symposium on stabilization of cells in the dry state. Cryobiology. 43:89-105 (2001).
116. K. L. Koster, M. S. Webb, G. Bryant, and D. V. Lynch. Interactions between soluble sugars and POPC (1-palmitoyl-2oleoylphosphatidylcholine) during dehydration: Vitrification of sugars alters the phase behavior of the phospholipid. Biochim. Biophys. Acta. 1193:143-150 (1994).

117. K. L. Koster, Y. P. Lei, M. Anderson, S. Martin, and G. Bryant. Effects of vitrified and nonvitrified sugars on phosphatidylcholine fluid-to-gel phase transitions. Biophys. J. 78:1932-1946 (2000).

118. J. Wolfe, and G. Bryant. Freezing, drying, and/or vitrification of membrane- solute-water systems. Cryobiology. 39:103-129 (1999).

119. G. R. Satpathy, Z. Torok, R. Bali, D. M. Dwyre, E. Little, N. J. Walker, F. Tablin, J. H. Crowe, and N. M. Tsvetkova. Loading red blood cells with trehalose: A step towards biostabilization. Cryobiology. 49:123-136 (2004).

120. Influenza Vaccine (Surface Antigen, Inactivated) European Pharmacopoeia, 5th ed, Council of Europe, Strasbourg, 2004 pp. 673-674.

121. S. Babiuk, D. M. Skowronski, G. De Serres, K. HayGlass, R. C. Brunham, and L. Babiuk. Aggregate content influences the Th1/Th2 immune response to influenza vaccine: Evidence from a mouse model. J. Med. Virol. 72:138-142 (2004).

122. H. J. Dean, and D. Chen. Epidermal powder immunization against influenza. Vaccine 23:681-686 (2004).

123. K. C. Bergmann, R. H. Waldman, H. Tischner, and W. D. Pohl Antibody in tears, saliva and nasal secretions following oral immunization of humans with inactivated influenza virus vaccine. Int. Arch. Allergy Appl. Immunol. 80:107-109 (1986).

124. Y. F. Maa, C. Shu, M. Ameri, C. Zuleger, J. Che, J. E. Osorio, L. G. Payne, and D. Chen. Optimization of an alum-adsorbed vaccine powder formulation for epidermal powder immunization. Pharm. Res. 20:969-977 (2003).

125. D. Chen, S. B. Periwal, K. Larrivee, C. Zuleger, C. A. Erickson, R. L. Endres, and L. G. Payne. Serum and mucosal immune responses to an inactivated influenza virus vaccine induced by epidermal powder immunization. J. Virol. 75:7956-7965 (2001)

126. D. Chen, M. Burger, Q. Chu, R. Endres, C. Zuleger, H. Dean, and L. G. Payne. Epidermal powder immunization: cellular and molecular mechanisms for enhancing vaccine immunogenicity. Virus Res. 103:147-153 (2004).

127. The European Agency for the Evaluation of Medicinal Products (EMEA) Committee for Proprietary Medicinal Products (CPMP). Note for Guidance on Harmonization of Requirements for Influenza Vaccines. CPMP/BWP/214/96 (1997).

128. V. J. Sullivan, J. A. Mikszta, P. Laurent, J. Huang, and B. Ford. Noninvasive delivery technologies: Respiratory delivery of vaccines. Expert Opin. Drug Deliv. 3:87-95 (2006).

129. M. T. Vidgren, and H. Kublik. Nasal delivery systems and their effect on deposition and absorption. Adv. Drug Deliv. Rev. 29:157-177 (1998).

130. S. P. Newman, G. R. Pitcairn, and R. N. Dalby. Drug delivery to the nasal cavity: in vitro and in vivo assessment. Crit. Rev. Ther. Drug Carrier Syst. 21:21-66 (2004).

131. B. L. Laube. The expanding role of aerosols in systemic drug delivery, gene therapy, and vaccination. Respir. Care 50:11611176 (2005).

132. Pulmonary drug delivery, Editio Cantor Verlag für Medizin und Naturwissenschaften GmbH, Aulendorf, 2007. 